\title{
A Nonstoichiometric Structural Model to Characterize Changes in the NiCKEL HYDROXIDE ELECTRODE DURING CYCLING
}

\author{
Venkat Srinivasan, ${ }^{1, *}$ Bahne C. Cornilsen, ${ }^{2}$ and John W. Weidner ${ }^{1}$ \\ 1. Center for Electrochemical Engineering \\ Department of Chemical Engineering \\ University of South Carolina \\ Columbia, SC 29208 \\ 2. Department of Chemistry \\ Michigan Technological University \\ 1400 Townsend Drive \\ Houghton, MI 49931
}

Manuscript Submitted to

The Journal of Solid State Electrochemistry

as a Technical Paper

Submission: September 15, 2003

Revised Submission: February 20, 2004

\footnotetext{
* Present address: Environmental Energy Technologies Division, Lawrence Berkeley National Laboratory, Berkeley, CA-94720 USA
} 


\begin{abstract}
Experimental capacities and mass changes are recorded using an electrochemical quartz crystal microbalance during the first 9 charge and discharge cycles of nickel hydroxide thin films cycled in 3.0 weight percent (wt\%) potassium hydroxide electrolyte. For the first time, the film capacities have been corrected for the oxygen evolution side reaction, and the data used as input into the point defect-containing structural model to track the changes that occur during short-term cycling. Variations in capacity and mass during formation and charge/discharge cycling are related to changes in the point defect parameters, thus providing a structural origin for the unique experimental variations observed here and often reported in the literature, but previously unexplained. Proton-, potassium-, and water-content vary in the active material during charge/discharge cycling. The observed capacity loss, or "capacity fade," is explained by incomplete incorporation of potassium ions in (or near) the nickel vacancy during charge, as additional protons are then allowed to occupy the vacant lattice site. The increase in water content during reduction parallels the expansion of the electrode that is well known during cycling. This result confirms the origin of the swelling phenomenon as being caused by water incorporation. The model and methodology developed in this paper can be used to correlate electrochemical signatures with material chemical structure.
\end{abstract}

Key Words: Nickel hydroxide, EQCM, point defect, nonstoichiometry, side reaction, water content 


\section{Introduction}

Nickel hydroxide is the positive electrode in a number of battery systems, namely, in $\mathrm{Ni}-\mathrm{Cd}, \mathrm{Ni}-\mathrm{MH}$ and $\mathrm{Ni}-\mathrm{H}_{2}$ cells [1]. In addition, the material finds application in electrochromic devices for use as "smart windows" [2,3]. The active material preparation often involves precipitation of the hydroxide from a nitrate salt solution, either by chemical or electrochemical techniques [4]. Depending on the preparation conditions, the electrochemical signatures of the active material are known to vary $[5,6]$. In addition, variations in capacity and voltage are also seen on cycling [7-9]. Two electrochemical cycles were identified in 1969, and four phases were proposed to explain the voltage differences in 1980 [5,10]. In 1988 and 1990 these four phases were shown to exhibit the same layer-type structure, and variations in empirical formulae were directly correlated with the nonstoichiometry and point defect structure [11,12].

Although most of the observed property variations remain unexplained, especially quantitatively, this paper shows that variations in $\mathrm{Ni}$ nonstoichiometry (i.e. nickel vacancies) and how these point defects are filled (or associated) with potassium cations or protons, can explain the varying properties through 9 charge/discharge cycles of an undoped nickel hydroxide film. These structural variations are monitored by simultaneously measuring the capacity and mass. It is shown that the defect parameter variation can be extracted from the mass and capacity data using a detailed reaction model and equations that relate the capacity/mass changes to the structural parameters.

The literature has shown that capacity and mass can be measured simultaneously using an electrochemical quartz crystal microbalance (EQCM) [7,8,13-16]. However, in 
the previous work, capacity could not be meaningfully linked with mass changes, because no account was made for the oxygen evolution reaction that is simultaneous with the nickel redox reaction. In the current paper, capacity measurements (corrected for $\mathrm{O}_{2}$ evolution) in $3.0 \mathrm{wt} \% \mathrm{KOH}$ electrolyte, are, for the first time, linked with EQCM mass changes, and these data are fitted using a point defect-containing structural model. This model contrasts with the previous literature models that assume a single, steady state redox reaction. Our premise is that these nonstoichiometric, structural variations explain the changes in electrochemical properties. The unique electrochemical characteristics of the nickel electrode, including the formation process and capacity loss during cycling, have been followed and quantitatively explained on the basis of chemical structural change.

In this paper the solid-state structural background, upon which the nonstoichiometric model is based, is first summarized. Then the point defect-containing, nonstoichiometric structural model is defined. After presenting experimental details, five reaction "scenarios" are presented in which the defect parameters are systematically varied in the nonstoichiometric structural model. These show how simple changes in defect parameters are linked to capacity variation during cycling. Finally, after better understanding how the defect parameters influence capacity in these qualitative scenarios, the point defect parameters are varied to fit the capacity/mass data. The resulting parameters define changes in the point defect structure, which quantitatively explain the observed property variation. 


\section{Background}

Bode and coworkers described the reactions occurring in the solid active material in terms of four phases, namely (i) an anhydrous phase termed $\beta-\mathrm{Ni}(\mathrm{OH})_{2}$, (ii) an hydrated phase termed $\alpha-\mathrm{Ni}(\mathrm{OH})_{2}$, and (iii) two oxidized phases, termed $\beta$-NiOOH or $\gamma$ $\mathrm{NiOOH}[10]$. Oxidation of $\beta-\mathrm{Ni}(\mathrm{OH})_{2}$ resulted in the formation of $\beta-\mathrm{NiOOH}$ while oxidation of $\alpha-\mathrm{Ni}(\mathrm{OH})_{2}$ resulted in $\gamma-\mathrm{NiOOH}$. The $\beta$ phase could transform to the $\gamma$ phase on overcharge, taking the material to the $\alpha-\gamma$ cycle, and the $\alpha$ phase could "convert" to the $\beta$ phase in concentrated alkali, returning the electrode to the $\beta-\beta$ cycle. This reaction scheme can be schematically represented as shown in equation 1 [10].

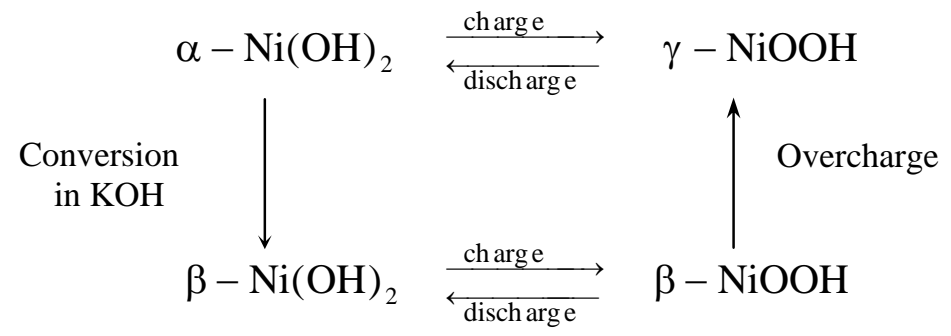

However, Raman spectroscopic studies on electrode active mass have indicated that these four electrochemically active materials actually share a common, nonclosepacked crystal structure (with ...ABBCCA... stacking). This common structure is indicated by the Raman spectral selection rules; these do not change during cycling [11,12]. Only the peak positions vary. This structure should be called the $\gamma$ structure (after the structure of the charged phase in the $\alpha-\gamma$ cycle [10]), and was confirmed by reanalysis of the $\gamma$ phase powder XRD pattern [11]. This structure contrasts with the closepacked, $\beta$-phase structure (with ...ABAB... stacking), which is electrochemically unstable under normal cycling conditions [5,11,12]. “Aging” active mass in concentrated 
alkali transform it into the $\beta$-phase structure $[5,11,12]$. These structural similarities and conversions or transformations are represented in a modified Bode diagram shown in equation 2 . Since the $2 \alpha-3 \gamma$ and the $2 \beta-3 \beta$ cycles involve materials that are nonclosepacked, ${ }^{*}$ there is no phase transition involved in going from one cycle to the other [12]. On the other hand, aging from the $2 \alpha$ to the $\beta$ involves a structural change as the $\beta$ material is close-packed.

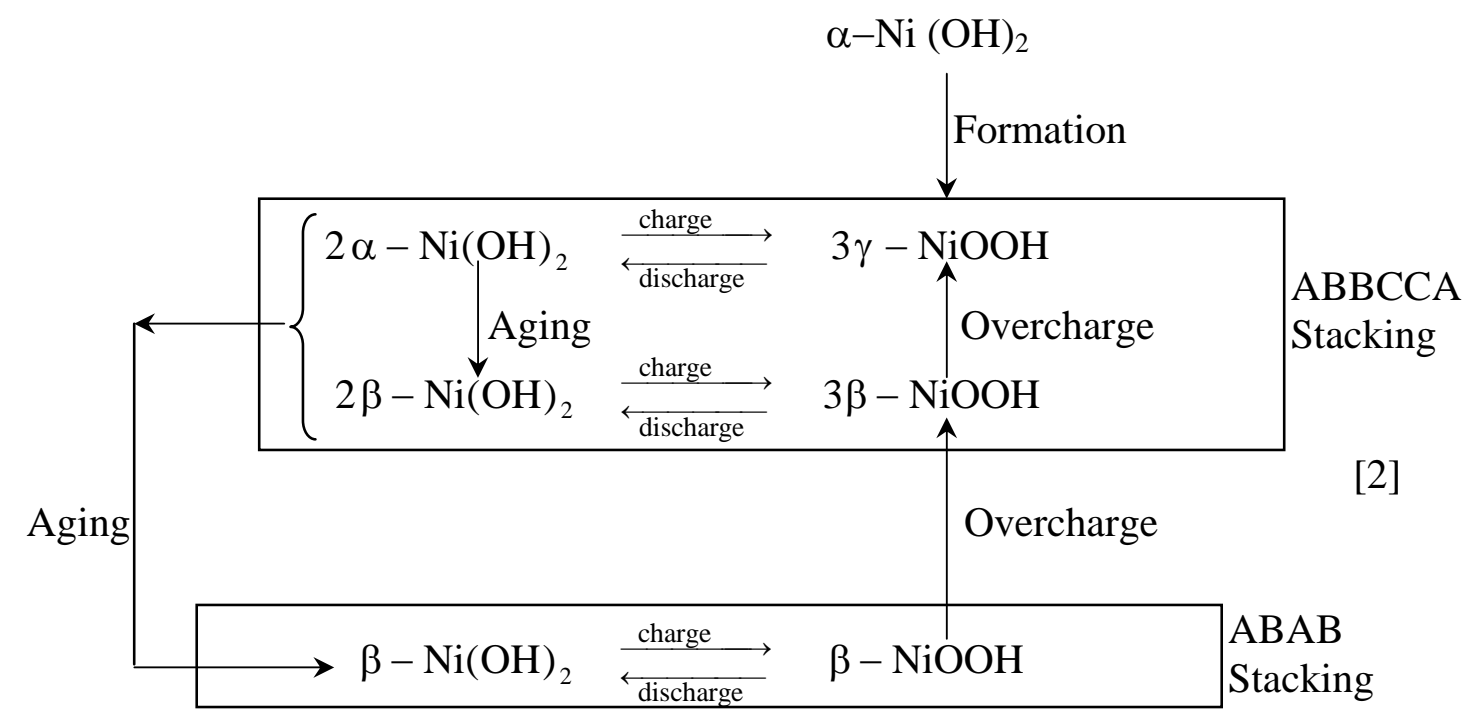

By combining the empirical formulae, observed by Barnard et al. [5,6], with the unit cell defined by the Raman and XRD data [11,12], these materials are seen to contain point defects and to be nonstoichiometric. Cornilsen et al. used this point defect approach to explain the differences in properties and structures of these various active

* These 4 end-member materials have the same crystal structure. This structure is different than those proposed for $\alpha-\mathrm{Ni}(\mathrm{OH})_{2}$ and $\beta-\mathrm{Ni}(\mathrm{OH})_{2}$. Coefficients, 2's and 3's, have been added to the traditional $\beta, \alpha$, and $\gamma$ designations of the "phases" to more clearly differentiate the unique materials, yet retain the connection to the older literature designations and eqn. 1 . Also the $\beta$ forms are unambiguously defined. 
materials [11,12]. The difference between the two Barnard cycles [5] (the two reactions represented in the upper rectangle) was found to be simply in the level of nickel vacancies, $\mathrm{V}_{\mathrm{Ni}}$, not differences in the crystal structures. The $2 \alpha-3 \gamma$ cycle was observed to have $25 \%$ nickel vacancy defects, while the $2 \beta-3 \beta$ cycle had $11 \%$ nickel vacancy defects $[11,12]$. These vacancies may either be occupied by protons, by potassium ions, or left vacant. This approach $[11,12]$ was used to explain some of the phenomena unique to the nickel electrode (e.g., existence of the maximum oxidation state of 3.67 as reported by Barnard et al. [5]). The Bode diagram and the Barnard et al. empirical formulae define two cycles, suggesting a finite number of distinct reactions. However, the nonstoichiometric model, with structural variation only in the point defect content (i.e. concentration variation) and in how the nonstoichiometry is accommodated within the ...ABBCCA... structure, actually simplifies these to one reaction with no phase transformations. In reality, this point defect approach argues that any reaction within this ...ABBCCA... structure is simply part of a structural continuum that depends on the concentrations of protons, alkali cations, Ni vacancies, and oxygen atoms present in the lattice. In this paper, we demonstrate how variation within this structural continuum, as shown in the modified Bode diagram, explains changes in the electrochemical properties of the nickel electrode properties during cycling.

Both the Bode diagram and the modified Bode diagram (eqns. 1 and 2) argue that in addition to the exchange of electrons, the lattice experiences exchange of protons and potassium ions during charge and discharge. In addition, atomic force microscopy (AFM) imaging $[17,18]$ suggests that electrolyte, presumably within the pores or between the crystallites, is exchanged during charge/discharge. Recognizing that such exchanges 
can be studied using an EQCM, numerous researchers have provided mass change data under various conditions (e.g., charge/discharge, [13,14] and long-term cycling [7,8,15].) The usefulness of the EQCM in measuring mass change, and not surface stress changes, was recently confirmed by Kim et al. [7] by using data on two different orientations of the quartz crystal. However, the interpretation provided by most authors is qualitative $[8,15]$. While some authors provide quantitative interpretation of the data (see Bernard et al. [14] and Cheek and O’Grady [13]), they do so using only the mass change along with an electrochemical reaction to extract water and electrolyte content in the films. Because the reactions used previously all represented a steady state cycle of the nickel electrode, phenomena such as capacity fade could not be described adequately.

In most studies capacity data have not been used as input along with the mass data because capacity measurement is complicated by the presence of the oxygen evolution side reaction. The true capacity of the nickel electrode can only be calculated by measuring nickel content and correcting for the oxygen side reaction. One study did attempt to use a structural model, capacity, and mass input, but did not correct for oxygen evolution [7]. Also, assumptions were made in that study [7] that limited the usefulness of the model, as discussed in the next section.

\section{The Point Defect Model}

The nickel hydroxide active material deposited using the cathodic precipitation technique produces porous films [19] with a considerable amount of electrolyte incorporated in the pores [20]. Therefore, the film can be considered as a collection of crystallites in a porous matrix, as seen in the schematic shown in Figure 1. 
Based on the previous structural (Raman and XRD evidence [11,12]) and chemical analyses, [11,12] these materials exhibit considerable nonstoichiometry $(0.11 \leq$ $\mathrm{x} \leq 0.25$ ). The empirical formulae can be rewritten to indicate this nonstoichiometry, and the point defects that accommodate it, as shown in equation 3. Additional water, $\mathrm{X}_{\mathrm{w}}$, (interlamellar and within the pores) is also indicated in this formula.

$$
\left[\mathrm{Ni}_{1-x}(\mathrm{~K})_{\mathrm{y}}(\mathrm{nH})_{\mathrm{x}-\mathrm{y}}\right] \mathrm{OOH}_{2-\mathrm{z}} \cdot \mathrm{X}_{\mathrm{w}} \mathrm{H}_{2} \mathrm{O}
$$

There is one mole of $\mathrm{Ni}$ sites per mole of $\mathrm{NiOOH}_{2-\mathrm{z}}$ within the unit cell that is defined on the basis of Raman and powder XRD data [11,12]. Therefore, $\mathrm{x}, \mathrm{y}, \mathrm{z}$, and $\mathrm{X}_{\mathrm{w}}$ are defined per mole of lattice sites in the unit cell. The nickel lattice is defective with nickel atoms missing from a fraction, $\mathrm{x}$, of the nickel-lattice sites. These sites can be vacant or contain other cations. An empty nickel site is referred to as a "nickel vacancy," and is represented by the notation $\mathrm{V}_{\mathrm{Ni}}$. Potassium ions occupy a fraction $\mathrm{y}$ of these nickel vacancies. Because the remaining nickel vacancies (x-y) are empty or occupied by 1,2 or 3 protons, the average proton occupancy is conveniently defined by n. In addition, there are two oxygen sites and two interlamellar proton sites per nickel-lattice site in the unit cell. The occupation of these proton sites (2-z) is allowed to vary. The state-ofcharge of the material, which is actually measured by the average oxidation state of the nickel, depends upon the $\mathrm{H}^{+}$and $\mathrm{K}^{+}$content of the vacant $\mathrm{Ni}$ sites and the interlamellar proton site content. We shall define the fully discharged state to contain two interlamellar protons $(\mathrm{z}=0)$, and the fully charged material is defined to contain one interlamellar proton $(\mathrm{z}=1)$. 
In Eqn. 3, $\mathrm{X}_{\mathrm{w}}$ represents the portion of electrode mass that is contributed by molecular water, both interlamellar water (which is part of the crystal structure) and water within the pores (between the crystallites). The portion of $X_{w}$ that is electrolyte within the pores can contain potassium ions. Any $\mathrm{K}^{+}$in this electrolytic water is balanced by $\mathrm{OH}^{-}$ions and does not take part in the chemical or electrochemical reactions, i.e. it does not contribute to the charge balance, nor influence $\mathrm{y}, \mathrm{x}$, or capacity. The concentration of this $\mathrm{KOH}$ need not be defined, which is fortunate because this concentration cannot be known exactly. It is only necessary that this $\mathrm{KOH}$ be accounted for as part of the total mass ( $\mathrm{KOH}$ plus water), and it is included within the mass from which $X_{w}$ is calculated.

Equations 4 and 5 relate the film oxidation state (Ox) and molecular weight (M) to the defect parameters defined in equation 3, and are written on a "per mole Ni" basis.

$$
\begin{aligned}
& O x=\left[\frac{(2+z)-y-n(x-y)}{1-x}\right] \\
& M=58.69+\frac{39.1 y+n(x-y)+34-z}{1-x}+18 \frac{X_{w}}{1-x}
\end{aligned}
$$

Ox is the average oxidation state.

The mechanisms that occur at the electrode/electrolyte interface during charging are sketched in Figure 1. Protons in the solid matrix diffuse to the surface of the crystallite and combine with hydroxyl ions to form water. Simultaneously, a potassium ion may intercalate into the crystallite and reside in or near the nickel vacancy. During this process, the oxidation state of nickel increases as an electron is ejected into the 
external circuit. The reverse of this process occurs on discharge. These processes combine to give the overall redox reaction in equation 6 . To describe this redox reaction, the formula in equation 3 must be put on a "per mole Ni" basis by dividing by $\left(1-\mathrm{x}_{\mathrm{i}}\right)$. Subscripts, $\mathrm{i}$, are added to the point defect variables to indicate the discharged (i=1) and charged (i=2) states. Equations 7-10 define the coefficients $\left(\lambda_{\mathrm{j}}\right)$ of $\mathrm{OH}^{-}, \mathrm{K}^{+}, \mathrm{H}_{2} \mathrm{O}$ and $\mathrm{e}^{-}$ in equation $6\left(\mathrm{j}=1-4\right.$, respectively) in terms of the changes in the 8 variables $\left(\mathrm{x}_{1}, \mathrm{y}_{1}, \mathrm{n}_{1}\right.$, $\mathrm{X}_{\mathrm{w} 1}, \mathrm{x}_{2}, \mathrm{y}_{2}, \mathrm{n}_{2}$, and $\mathrm{X}_{\mathrm{w} 2}$ ). These also balance the redox reaction. Equation 6 defines the point defect structures of the two extreme, or end-member materials upon discharge and charge (i.e., at $\mathrm{z}=0$ and $\mathrm{z}=1$, respectively), as discussed above. An equation analogous to equation 6 could be written for intermediate oxidation states by including $\mathrm{z}$ as a variable.

$$
\begin{aligned}
& {\left[\mathrm{Ni}(\mathrm{K})_{\frac{\mathrm{y}_{1}}{\left(1-\mathrm{x}_{1}\right)}}\left(\mathrm{n}_{1} \mathrm{H}\right)_{\frac{\mathrm{x}_{1}-\mathrm{y}_{1}}{1-\mathrm{x}_{1}}}\right]_{\frac{2}{1-\mathrm{x}_{1}}} \frac{\mathrm{H}_{2}}{1-\mathrm{x}_{1}} \cdot \frac{\mathrm{X}_{\mathrm{w}_{1}}}{1-\mathrm{x}_{1}} \mathrm{H}_{2} \mathrm{O}+\lambda_{1} \mathrm{OH}^{-}+\lambda_{2} \mathrm{~K}^{+}} \\
& \stackrel{\text { charge }}{\underset{\text { discharge }}{\longrightarrow}}\left[\mathrm{Ni}(\mathrm{K})_{\frac{\mathrm{y}_{2}}{\left(1-\mathrm{x}_{2}\right)}}\left(\mathrm{n}_{2} \mathrm{H}\right)_{\frac{\mathrm{x}_{2}-\mathrm{y}_{2}}{1-\mathrm{x}_{2}}}\right] \mathrm{O}_{\frac{2}{1-\mathrm{x}_{2}}} \mathrm{H}_{\frac{1}{1-\mathrm{x}_{2}}} \cdot \frac{\mathrm{X}_{\mathrm{w}_{2}}}{1-\mathrm{x}_{2}} \mathrm{H}_{2} \mathrm{O}+\lambda_{3} \mathrm{H}_{2} \mathrm{O}+\lambda_{4} \mathrm{e}^{-}
\end{aligned}
$$

$$
\begin{aligned}
& \lambda_{1}=\left[\frac{\mathrm{n}_{1}\left(\mathrm{x}_{1}-\mathrm{y}_{1}\right)-2}{\left(1-\mathrm{x}_{1}\right)}-\frac{\mathrm{n}_{2}\left(\mathrm{x}_{2}-\mathrm{y}_{2}\right)-3}{\left(1-\mathrm{x}_{2}\right)}\right] \\
& \lambda_{2}=\left[\frac{\mathrm{y}_{2}}{\left(1-\mathrm{x}_{2}\right)}-\frac{\mathrm{y}_{1}}{\left(1-\mathrm{x}_{1}\right)}\right] \\
& \lambda_{3}=\left[\frac{\mathrm{n}_{1}\left(\mathrm{x}_{1}-\mathrm{y}_{1}\right)}{\left(1-\mathrm{x}_{1}\right)}-\frac{\mathrm{n}_{2}\left(\mathrm{x}_{2}-\mathrm{y}_{2}\right)-1}{\left(1-\mathrm{x}_{2}\right)}\right]+\frac{\mathrm{X}_{\mathrm{w}_{1}}}{1-\mathrm{x}_{1}}-\frac{\mathrm{X}_{\mathrm{w}_{2}}}{1-\mathrm{x}_{2}}
\end{aligned}
$$




$$
\lambda_{4}=\left[\frac{3-\mathrm{y}_{2}-\mathrm{n}_{2}\left(\mathrm{x}_{2}-\mathrm{y}_{2}\right)}{\left(1-\mathrm{x}_{2}\right)}-\frac{2-\mathrm{y}_{1}-\mathrm{n}_{1}\left(\mathrm{x}_{1}-\mathrm{y}_{1}\right)}{\left(1-\mathrm{x}_{1}\right)}\right]
$$

Equation 6 can be used to represent specific reactions shown in the modified Bode diagram. For example, the $\alpha$ to $3 \gamma$ reaction (termed "formation" in eqn. 2) can be obtained by substituting $\mathrm{x}_{1}=\mathrm{x}_{2}=\mathrm{y}_{2}=0.25, \mathrm{n}_{1}=2$ and $\mathrm{y}_{1}=0$ into eqns. 6-10, giving the reaction in eqn. $11[11,12]$.

$$
\begin{aligned}
& {\left[\mathrm{Ni}^{2.0}(2 \mathrm{H})_{0.33}\right] \mathrm{O}_{2.67} \mathrm{H}_{2.67}+2 \mathrm{OH}^{-}+0.33 \mathrm{~K}^{+}} \\
& \stackrel{\text { Formation }}{\longrightarrow}\left[\mathrm{Ni}^{3.67}(\mathrm{~K})_{0.33}\right] \mathrm{O}_{2.67} \mathrm{H}_{1.33}+2 \mathrm{H}_{2} \mathrm{O}+1.67 \mathrm{e}^{-}
\end{aligned}
$$

These two defect formulae correspond to the Barnard et al. empirical formulae for these two end-member materials $[5,10,21]$. The superscript on each Ni atom indicates the average nickel oxidation state (per eqn. 4). When the material is charged during the formation step, 1.0 interlamellar protons are removed per Ni site, or 1.34 interlamellar protons per Ni atom. Also, all the protons on the nickel vacancies are replaced by potassium ions (i.e. , $\mathrm{y}_{2}=\mathrm{x}_{2}$ ), to give a net loss of 2.0 protons and 1.67 electrons per $\mathrm{Ni}$ atom. Since protons occupy none of the nickel vacancies, the value of $n_{2}$ is 0 .

After the formation, the $2 \alpha-3 \gamma$ reaction can be obtained by substituting $\mathrm{x}_{1}=\mathrm{x}_{2}=\mathrm{y}_{2}=0.25, \mathrm{n}_{1}=0, \mathrm{n}_{2}=0$, and $\mathrm{y}_{1}=0$ into eqns. $6-10$, to give eqn. $12[11,12]$.

$$
\begin{aligned}
& {\left[\mathrm{Ni}^{2.67}\left(\mathrm{~V}_{\mathrm{Ni}}\right)_{0.33}\right] \mathrm{O}_{2.67} \mathrm{H}_{2.67}+1.33 \mathrm{OH}^{-}+0.33 \mathrm{~K}^{+}} \\
& \underset{\text { charge }}{\stackrel{\text { disch arge }}{\rightleftarrows}}\left[\mathrm{Ni}^{3.67}(\mathrm{~K})_{0.33}\right] \mathrm{O}_{2.67} \mathrm{H}_{1.33}+1.33 \mathrm{H}_{2} \mathrm{O}+1 \mathrm{e}^{-}
\end{aligned}
$$

The discharge of the $3 \gamma$ material involves the incorporation of interlamellar protons, and the release of potassium ions from the nickel vacancies [11,12]. However, the discharged material does not contain protons on the nickel vacancies as did the as-deposited material 
of eqn. 11 (see left-hand side). Consequently, the oxidation state of the $2 \alpha$ material is 2.67 rather than the 2.0 of the $\alpha$ material. This change in point defect structure explains the change of 1 electron/Ni as observed by Corrigan and Knight [22] and by Barnard, et al. [5].

Similarly, the $2 \beta-3 \beta$ cycle is considered to exhibit a defect content of 0.11 $[11,12]$. This reaction is obtained by substituting $\mathrm{x}_{1}=\mathrm{x}_{2}=0.11, \mathrm{n}_{1}=0, \mathrm{y}_{1}=\mathrm{y}_{2}=0$ and $\mathrm{n}_{2}=1$ as shown in eqn. 13. These formulae are again comparable to the empirical formulae reported in the literature [5]. In contrast to the $2 \alpha-3 \gamma$ cycle, each vacancy in the $2 \beta-3 \beta$ cycle exchanges a proton rather than a potassium ion. Again a $1 \mathrm{e}^{-}$change/Ni is predicted. However, if the charged material contains more than 1 proton per vacancy, then the electron change will be less than one. The empirical formula given by Barnard et al.[5,6] actually corresponds to a material with 3 protons per $\mathrm{V}_{\mathrm{Ni}}$. It is important to keep in mind that reactions $11-13$ are in reality three examples of what is really a continuum of structures, all of which are represented by reaction 6 .

$$
\begin{aligned}
& {\left[\mathrm{Ni}^{2.25}\left(\mathrm{~V}_{\mathrm{Ni}}\right)_{0.12}\right] \mathrm{O}_{2.25} \mathrm{H}_{2.25}+\mathrm{OH}^{-}} \\
& \underset{\text { charge }}{\stackrel{\text { disch arge }}{\rightleftarrows}}\left[\mathrm{Ni}^{3.25}(\mathrm{H})_{0.12}\right] \mathrm{O}_{2.25} \mathrm{H}_{1.12}+\mathrm{H}_{2} \mathrm{O}+1 \mathrm{e}^{-}
\end{aligned}
$$

While Kim et al.[7] also used the defect model developed by Cornilsen et al.[23] to analyze their data, they assumed that all variations in capacity occurred due to incomplete removal of interlamellar protons on charge (i.e., $\mathrm{z}<1$ ). They also assumed that the discharged material contained one proton per nickel vacancy (i.e., $\mathrm{n}_{1}=1, \mathrm{y}_{1}=0$, $\mathrm{x}_{1}=0.25$ ), and that on charge this proton was replaced with a potassium ion (i.e., $\mathrm{y}_{2}=\mathrm{x}_{2}=0.25$ ). The limitation of their assumptions is that changes in mass and capacity 
were linked through a single parameter, z. More importantly, their assumptions limited the ability of the point defect model to correctly fit their data in several ways. First, they were unable to explain the large capacity seen during the first charge (i.e., formation). As we shall see, this is because they set $\mathrm{n}_{1}$ equal to 1 . The authors ignore experimental data from the first charge, the formation process. Finally, using $n_{1}=1$ with a defect content of 0.25, the maximum oxidation state for nickel is limited to 3.33, which is well below the reported literature value of 3.67 [15,22]. This prevented them from understanding any process involving an oxidation state above 3.33, e.g. any fading process involving a higher oxidation state.

\section{Experimental}

Films of nickel hydroxide were deposited electrochemically on a $0.196 \mathrm{~cm}^{2}$ gold substrate sputtered on a quartz crystal in a procedure described in detail elsewhere $[20,24]$. Prior to deposition, the crystals were immersed for a few seconds in a freshly prepared 3:1 mixture of concentrated sulfuric acid and hydrogen peroxide (Piranha reagent) and then rinsed of reagents using deionized water (resistivity $18 \mathrm{M} \Omega$-cm). The films were deposited at room temperature in a bath containing $1.8 \mathrm{M} \mathrm{Ni}\left(\mathrm{NO}_{3}\right)_{2}$ and 0.075 $\mathrm{M} \mathrm{NaNO}_{3}$ in a solvent of $50 \%$ v/o ethanol using a cathodic current of $1.0 \mathrm{~mA}$ (5.1 $\mathrm{mA} / \mathrm{cm}^{2}$ ). The mass of the film was monitored using an EQCM (EG\&G model QA-917), and the current was switched off once the mass reached $67 \mu \mathrm{g}$. It was observed that deposition continued as a result of the alkaline $\mathrm{pH}$ at the electrode surface. Once the mass change was negligible, the deposition solution was quickly drained from the cell and the deposited film was washed in deionized water. This procedure resulted in films of mass $69.1 \pm 0.1 \mu \mathrm{g}$. In order to determine the moles of $\mathrm{Ni}$ in a film, five films were 
stripped with $1.0 \mathrm{ml}$ of dilute nitric acid $(\mathrm{pH}=1.0)$ and further flushed with $3.0 \mathrm{ml}$ of degassed, deionized water. The resulting $4.0 \mathrm{ml}$ of solution was injected into an ionchromatograph (DIONEX) and the moles of nickel were determined from the concentration and volume of solution. Dividing the mass of the film by the moles of nickel gave an average molecular weight for the five films of $121 \pm 6$ grams of asdeposited material per mole of nickel. Films cycled in 3\% KOH for 25 cycles were found to have a similar nickel content, indicating no loss of nickel on cycling.

For galvanostatic charge/discharge experiments, aqueous $3.0 \mathrm{wt} \% \mathrm{KOH}$ solution was placed in the EQCM cell containing a nickel hydroxide film. These studies were carried out in $3.0 \mathrm{wt} \% \mathrm{KOH}$ so as to maintain the system in the $\alpha-\gamma$ electrochemical cycle. Low $\mathrm{KOH}$ concentration favors the $\alpha-\gamma$ cycle. Higher $\mathrm{KOH}$ concentrations, although used in commercial batteries, favor aging to the $\beta-\beta$ electrochemical cycle., ${ }^{5,11,12}$ The cell also contained a SCE reference and a platinum counter electrode. An EG\&G M273 potentiostat/galvanostat was used to control the current, and the mass was monitored by the EQCM. Experimental control and data acquisition were achieved using the M270 software.

\section{Experimental Results}

Figure 2 shows the potential profiles for the first two charge and discharge cycles for a $69.1 \mu$ g nickel hydroxide film. On charge, the oxidation of nickel is the main reaction between the 0.30 and $0.33 \mathrm{~V}$ vs. SCE. However, at these voltages a fraction of the current is also going into the oxygen evolution reaction

$$
4 \mathrm{OH}^{-} \rightarrow \mathrm{O}_{2}+2 \mathrm{H}_{2} \mathrm{O}+4 \mathrm{e}^{-} \quad 0.175 \mathrm{~V} \text { vs. SCE }
$$


As the nickel becomes fully oxidized (i.e., $\mathrm{z} \rightarrow 1$ ), more of the current goes into reaction 14 and the voltage rises. At approximately $0.425 \mathrm{~V}$, the material is fully charged and oxygen evolution becomes the sole reaction. Figure 2 also shows the potential profiles on discharge. The sharp drop in potential at long times corresponds to the end of discharge (i.e., $\mathrm{z}=0$ ).

Potential profiles similar to those shown in Figure 2 were used to calculate the capacity transferred to or removed from the film per original mass of film, Q. The capacity is the product of the time required to fully charge or discharge the material, $\tau$ (designated by $\times$ on Figure 2), and the applied current. The resulting charge and discharge capacities for 9 cycles are shown in Figure 3, where the symbols are a mean of 3 - 4 data sets and the error bars represent the high and low values. The larger error bars on the charge compared to the discharge are due to greater uncertainty in identifying the end-of-charge point, as these are not as clearly defined on the curve. The greater capacity on charge is due to the increased oxygen evolution compared to discharge. In order to estimate the true capacity of the nickel electrode, the data in Figure 2 must be corrected for the oxygen reaction.

The following equation is used to convert the capacity in Figure 2 to electrons transferred per nickel

$$
\lambda_{4}=\frac{\varepsilon \mathrm{QM}_{1}^{0}}{\mathrm{~F}}
$$

where $\mathrm{M}_{1}^{0}$ is the molecular weight of the film in the as-deposited state (121 g/mole Ni). $\varepsilon$ is the fraction of the applied current that has gone into the nickel reaction during the 
course of the charge or discharge. This quantity was evaluated by correcting for the oxygen evolution reaction as described previously [25].

This procedure was repeated for each of the films for the $1^{\text {st }}, 6^{\text {th }}$ and $9^{\text {th }}$ cycle. It was found that the charges were approximately 17 - 20\% inefficient, and the discharges were only 0.6 - 2\% inefficient. Accounting for this inefficiency, it was seen that the charge and discharge capacities were within $2 \%$ of each other. Therefore, past the $1^{\text {st }}$ cycle the capacity of the film on charge is the same as the capacity on the subsequent discharge. The electrons transferred per nickel are shown in Figure 4. Again, the symbols are a mean of 3 - 4 data sets, and the error bars represent the high and low values. These data exhibit three characteristics that are consistent with previous literature observations: (a) approximately 1.67 electrons per nickel are transferred in the first charge [22]; (b) 1.0 electron per nickel is transferred during the subsequent discharge and charge [22]; and (c) the following discharge and charge capacities steadily decrease with cycling [8,15]. It should be noted that the less than 1 electron estimated in this figure cannot be explained by the traditional $\alpha-\gamma$ and the $\beta-\beta$ cycles as both these reaction suggest electron transfers $\geq 1.0$.

Using the average number of electrons transferred and considering that the asdeposited material has an oxidation state of 2.0 , the variation in oxidation state is calculated as shown in Figure 5. As the material is cycled, the discharged state reaches a steady value close to 2.6. The charged material, on the other hand, starts with an oxidation state of 3.63 and on cycling the oxidation state drops to 3.39 by the ninth cycle in a manner consistent with Figure 4 (i.e., consistent with the number of e ${ }^{-}$transferred). 
It is worth noting that a 3.67 upper oxidation state of the charged electrode (resulting from a 1.67 electron transfer) has previously been argued from oxidation state measurements done by chemical titration $[5,10,21]$. The data in Figure 4 show the first robust estimate of this number based on counting coulombs and correcting for the side reaction. Note that Corrigan and Knight [22] attempted to estimate this number by counting coulombs; they did so by arbitrarily assuming that the main reaction was the sole reaction until the potential was $20 \mathrm{mV}$ below the oxygen evolution plateau, at which point, the reaction was assumed to be complete. In addition, the data in Figures 4 and 5 show that although the capacity on charge is all recovered on discharge, the electrode exhibits capacity fade. Furthermore, these data argue that the fade is caused by an inability to charge the electrode to a higher oxidation state. This contrasts with other explanations of capacity fade which suggest that the cause is the inability to discharge at this potential and the need for a greater driving force (the formation of the so-called “second discharge plateau”).

Using the EQCM, the mass change of the film was also monitored during charge and discharge. The results from the first two cycles are shown in Figure 6 as a function of time. Consistent with previous results, the mass of the film increased on charge and decreased on discharge $[7,8,15,16]$. In addition, the mass change is negligible at the end of the charge as the oxygen evolution reaction does not produce a mass change. The total change in mass following complete charge and discharge is shown in Figure 7 for the first 9 cycles and is represented as the change in molecular weight (weight change divided by number of moles of $\mathrm{Ni}$ ). Again, the symbols are a mean of 3 - 4 data sets, and the error bars represent the high and low values. The magnitude of the mass change is 
greater on charge than on the discharge, as is clearly seen in Figure 6. This is true for all cycles, and it results in an overall increase in the mass of the film on cycling. This is consistent with previous observations [16] Although the total mass of the film increases with cycling, the mass change from cycle to cycle decreases. For example, the mass reduction during the first discharge was approximately $5.3 \mathrm{~g} / \mathrm{mole} \mathrm{Ni}$, but that for the ninth discharge was only $3.3 \mathrm{~g} / \mathrm{mole} \mathrm{Ni}$.

\section{Qualitative Influence of Defect Parameters on Capacity; 5 Scenarios}

In this section, 5 scenarios are presented to demonstrate how systematic variation of certain defect parameters influences the capacity (i.e. the number of electrons transferred). These provide a qualitative picture of the changes in structure of the films during early cycling and show which parameters are likely to change in order to be consistent with five experimental observations noted previously. In summary, these five observations are: (a) 1.67 electrons per nickel are transferred in the first charge; [22] (b) 1.0 electrons per nickel are transferred during the subsequent discharge and charge ; [22] (c) the charge and discharge capacities decrease with further cycling; [8,15] (d) the total mass of the film increases with cycling; [16] and (e) the mass of the film increases on charge and decreases on discharge $[7,15,16]$. To provide this qualitative picture, the defect model and equation 10 are utilized to predict changes in capacity of the active material during successive charge/discharge cycles using appropriate values of the defect parameters $\mathrm{x}_{\mathrm{i}}, \mathrm{y}_{\mathrm{i}}$, and $\mathrm{n}_{\mathrm{i}}$. Comparison of these predictions with experiment provides insight into which parameters are changing as nickel hydroxide films are cycled. Equation 10 does not include the mass effects (observations $d$ and e), but the predicted 
qualitative changes in mass accompanying these capacity variations must be consistent with the observed mass changes.

Although one could study numerous combinations of the eight defect parameters (four each, $\mathrm{x}_{\mathrm{i}}, \mathrm{y}_{\mathrm{i}}, \mathrm{n}_{\mathrm{i}}$, and $\mathrm{Xw}_{\mathrm{i}}$, in the charged and discharged state), five scenarios are presented, as listed in Table 1. These not only provide insight into how these parameters affect capacity, these also reflect the reaction models postulated in the literature to explain observed capacity and mass changes during cycling. The number of electrons transferred for each charge and discharge is calculated using equation 10, as a function of cycle number and the defect parameter variations listed in Table 1. For illustrative purposes, the parameters are varied linearly with cycle number. The number of electrons transferred per nickel vs. cycle number for scenarios 1 - 3 is plotted in Figure 8, and those for scenarios 4 and 5 are plotted in Figure 9.

Scenario 1 describes a $2 \alpha-3 \gamma$ cycle (i.e., $\mathrm{x}=0.25$ ), where $\mathrm{K}^{+}$is inserted on charge and progressively more of the potassium ions remain on the Ni vacancies with cycling upon each discharge (i.e., $\mathrm{y}_{1}$ increases from 0 to 0.25). Scenario 2 describes the conversion of the material from the $2 \alpha-3 \gamma$ to the $2 \beta-3 \beta$ cycle (i.e., $x$ decreases from 0.25 to 0.11 ). For illustrative purposes, the decrease in defect content is assumed to occur on the discharge while on charge the defect content is unchanged. As the defect content of the film decreases with cycling, so does the amount of potassium exchanged. On discharge, two protons replace the potassium ions on the nickel vacancies (i.e., $\mathrm{n}_{1}=2$ ). Scenario 3 describes a film converting from the $2 \beta-3 \beta$ to the $2 \alpha-3 \gamma$ cycle (i.e., $x$ increases from 0.11 to 0.25 ). Here, the increase in $x$ has been taken to occur on the 
charge, with $\mathrm{x}$ unchanged on discharge. However, unlike scenario 2, no protons replace the potassium ions on discharge (i.e., $\mathrm{n}_{1}=0$ ). Scenario 4 describes a $2 \alpha-3 \gamma$ cycle (i.e., $\mathrm{x}$ $=0.25$ ), where progressively less of the potassium ions are incorporated on the $\mathrm{Ni}$ vacancies during charge (i.e., $\mathrm{y}_{2}$ decreases from 0.25 to 0.11 ). The vacancies not filled with potassium are instead filled with two protons (i.e., $\mathrm{n}_{2}=2$ ). Scenario 5 is a combination of scenarios 2 and 4 , where the material is converting from the $2 \alpha-3 \gamma$ to the $2 \beta-3 \beta$ cycle with two protons replacing potassium ions on the Ni vacancy during charge. Note that the potassium ion content decreases at a greater rate than the decrease in the defect content. All five scenarios involve incorporation of potassium ions into the $\mathrm{Ni}$ vacancy on charge, which is consistent with observation (e), i.e., a mass increase is observed on charge.

Figure 8 reveals that scenario 1 results in a 1.67 electron transfer per nickel in the first charge and $a \approx 1.0$ electron transfer in the subsequent discharge, consistent with observations (a) and (b). However, this scenario results in an increase in capacity on cycling, which is inconsistent with observation (c). As progressively less potassium is exchanged, the change in the oxidation state of nickel increases. Therefore, one can conclude that the increase in mass on cycling, observation (d), is not due to an increase in the amount of potassium ions remaining on the $\mathrm{Ni}$ vacancy, as suggested by previous researchers [16].

While scenario 1 shows an increase in capacity on cycling, scenario 2 exhibits a decrease in capacity, consistent with observation (c). However, this decrease in capacity with cycling occurs steadily from 1.67 to 1.25 electrons per nickel, which is inconsistent 
with observation (b). This large electron transfer $(>1)$ on discharge is due to the replacement of potassium ions with two protons. Since $n_{1}=2$, the oxidation state of the discharged material is 2.0 after each cycle. The oxidation state of the charged material decreases steadily from 3.67 to 3.25 . If $n_{1}$ were set equal to 1 , rather than to 2 , the number of electrons transferred would decrease from 1.3 to 1.1 for cycles $2-9$, and if $\mathrm{n}_{1}=0$ a 1.0 electron transfer would occur during each cycle. These results are in disagreement with observations (b) and (c), respectively.

In contrast to scenarios 1 and 2, scenario 3 predicts a slight decrease in the discharge capacity on cycling as the number of electrons transferred decreases from 0.95 to 0.94 . However, the first charge results in a 1.25 electron transfer as opposed to the 1.67 electron transfer noted in observation (a). This is a consequence of starting with a defect content of $x=0.11$. The only way to achieve a 1.67 electron transfer on the first charge is to start with a defect content of $x=0.25$.

While scenarios 1 - 3 show results that are inconsistent with one or more of the experimental observations (a) - (e), scenarios 4 and 5 (shown in Figure 9) are consistent with all 5 observations. The reason these scenarios are consistent with the experimental observations is that progressively less of the potassium ions are incorporated onto the $\mathrm{Ni}$ vacancies during charge. Filling a nickel vacancy with two protons in the charged state rather than a potassium ion results in a decrease in the oxidation state of the charged material in order to compensate for the extra positive charge. In scenario 4, the oxidation state of the discharge material remains at 2.67 , and therefore the number of electrons transferred decreases. 
Scenario 5 is similar to scenario 2 in that both result in a decrease in capacity on cycling. The major qualitative difference between these two scenarios, though, is that scenario 2 shows a steady decrease in capacity with cycling while scenario 5 shows a sharp capacity decrease between cycles 1 and 2 . The discontinuity in scenario 5 is due to the fact that there are no protons in the discharged material past the as-deposited state. This means 1.67 electrons are removed on the first charge but only 1.0 electrons are reinserted on the subsequent discharge. In contrast, scenario 2 always has two protons reintercalated into the defects after each discharge, thus allowing 1.67 electrons to be reinserted during the first discharge.

Although both scenarios (2 and 5) show a steady decrease in capacity during cycles 2 - 9, this decrease occurs for different reasons. In scenario 2, the oxidation state of the discharged material is always 2.0 because $\mathrm{y}_{1}=0$ and $\mathrm{n}_{1}=2$, but the oxidation state of the charged material decreases because the defect content decreases. In scenario 5, both the oxidation state of the charged and discharged material decreases as $\mathrm{x}$ decreases. However, the oxidation state of the charged material decreases faster than the discharged material resulting in a net decrease in the number of electrons transferred. This greater decrease in the charged state is caused by $\mathrm{y}_{2}$ being less than $\mathrm{x}_{2}$. If $\mathrm{y}_{2}$ were equal to $\mathrm{x}_{2}$ then the number of electrons transferred would be 1.0 for each cycle except for the first charge. The greater the difference between $\mathrm{y}_{2}$ and $\mathrm{x}_{2}$, the larger the decrease in capacity. Note that intercalation of three protons rather than two in scenarios 4 and 5 would also show a decrease in capacity with cycle number, but the decrease would be even greater.

The decrease in capacity seen in scenarios 4 and 5 can also be achieved by setting $\mathrm{x}_{1}=0.25$ and $\mathrm{n}_{1}=0$. This would fix the oxidation state of the discharge material at 2.67. 
Then if $x_{2}$ progressively decreased on each cycle, with $y_{2}=x_{2}$, the oxidation state of the charged material would decrease, thus decreasing the capacity.

From these five different scenarios, some broad conclusions can be drawn on the possible ways to explain the experimental observations of cycled nickel hydroxide.

1. The 1.67 electron transfer on the first charge can only be achieved by starting with a defect content of $x=0.25$ and removing a net positive charge from each Ni vacancy. The net result is a nickel oxidation state of 3.67 after the first charge. Coupling this with a mass increase on charge, observation (e), it is most likely that the removal of a positive charge from the Ni vacancy occurs via the exchange of 2 protons with one $\mathrm{K}^{+}$as opposed to removing one proton with no potassium exchange.

2. The 1.0 electron transfer in the first discharge is only possible by having an empty vacancy on discharge (i.e., $\mathrm{n}_{1}=0$ and $\mathrm{y}_{1}=0$ ). Although a 1.0 electron transfer would occur regardless of the value for $\mathrm{x}$, taking observations (a) and (b) together means $\mathrm{x}=$ 0.25, and the oxidation state of nickel on the first discharge goes from 3.67 to 2.67 .

3. The decrease in capacity of the active material below 1.0 electrons transferred per nickel can be achieved by (i) increasing the oxidation state of the discharged phase to above 2.67 and/or (ii) decreasing the oxidation state of the charged phase to below 3.67. The experimental data shown in Figure 5 indicate that the latter is the cause for this decrease. That is, the capacity decrease is caused by a decrease in the oxidation state of the charged material. This decrease could occur by either progressively filling the Ni vacancy with more than one charge-compensating ion (i.e., two or more $\mathrm{K}^{+}$or $\mathrm{H}^{+}$) or by decreasing $\mathrm{x}_{2}$ with cycling while keeping $\mathrm{x}_{1}$ constant. This latter 
scenario seems unlikely since the defect content would be increasing and decreasing significantly during each charge/discharge cycle. It is unlikely that this repeated expanding and contracting of the lattice could occur on the time scale of each cycle. This oscillating defect content would also put undue stress on the crystal lattice. Therefore, the steady decrease in the oxidation state of the discharged material is most likely due to the filling of the $\mathrm{Ni}$ vacancy with more than one chargecompensating ion. The size of a potassium ion makes it improbable that two of these cations can be accommodated on one vacancy. It is more likely that an increasing number of vacancies are filled with more than one proton (i.e., $\mathrm{n}_{2}>1$ ) on cycling. For this to occur, $\mathrm{y}_{2}$ must decrease and/or $\mathrm{n}_{2}$ must increase with cycling.

\section{Extracting Defect Parameters from Experimental Data}

Two of the four defect parameters $\left(\mathrm{x}_{\mathrm{i}}, \mathrm{y}_{\mathrm{i}}, \mathrm{n}_{\mathrm{i}}\right.$, and $\left.\mathrm{X}_{\mathrm{wi}}\right)$ which define each state-ofcharge, discharged ( $\mathrm{i}=1)$ and charged $(\mathrm{i}=2)$, are evaluated sequentially by coupling the capacity and mass change data (as molecular weight) in Figures 4 and 7 with equations 4 , 5 and 10. The other two defect parameters must be defined by other means.

The defect parameters $[11,12]$ in the as-deposited material are fully defined by using the molecular weight of the as-deposited material (i.e., $121 \mathrm{~g} / \mathrm{mol} \mathrm{Ni}$ ) and the following two experimental observations [5,10,21]: First, the as-deposited material has a nickel oxidation state of 2.0. Secondly, the as-deposited material contains no potassium; therefore, nickel vacancies in this material are void of potassium (i.e., $\mathrm{y}_{1}=0$ ). Coupled with observation 1 , this means that $n_{1}=2$. The value of $x_{1}$ will be taken to be equal to the value of $x_{2}$ obtained during the first charge (0.25), as explained in the following 
paragraph. These three defect parameters, $\mathrm{n}_{1}=2, \mathrm{y}_{1}=0$, and $\mathrm{x}_{1}=0.25$, together with the molecular weight, allow calculation of the water content for the as-deposited material, $\mathrm{X}_{\mathrm{w} 1}^{0}$, as 0.69 moles of water per mole of lattice sites. Note that $\mathrm{X}_{\mathrm{w} 1}$ is actual, molecular water (i.e. interlamellar or pore water) and is different than the $0.67 \mathrm{H}_{2} \mathrm{O}$ reported by Bode et al. [26] and by Barnard et al. [5] for the "activated" $\alpha$ phase material. The water reported in the Bode et al. empirical formula (where $\mathrm{y}=0.67$ ) is accounted for in the nonstoichiometric formula as $\mathrm{y}$ additional $\mathrm{OH}^{-}$groups and $\mathrm{y} / 2$ additional $\mathrm{V}_{\mathrm{Ni}}$ which contain y protons [11,12].

The value of $x_{2}$ will be held at 0.25 for this calculation. It is necessary to hold either $\mathrm{x}_{2}$ or $\mathrm{y}_{2}$ constant in the calculation of the charged state defect parameters. It is not possible to vary both $\mathrm{y}_{2}$ and $\mathrm{x}_{2}$ simultaneously. $\mathrm{x}_{2}$ will be held constant at this value for three reasons. First of all, this value is consistent with $\mathrm{x}_{1}$ values measured for cathodic- $\alpha$ phases and charged phases in the literature [11,12]. Secondly, a high value for $\mathrm{x}_{2}$ is consistent with the 1.55-1.67 electron change observed (Figure 4) and the upper oxidation state (3.63) obtained during this first charge (Figure 5). The latter is gotten from the 1.63 electron change observed in the first charge (Figure 4) relative to the 2+ oxidation state of the as-deposited material (experimental observation 1, above). Any decrease in oxidation state from the 3.67 maximum will then be accounted for by an increase in $y_{2}$. Finally, an $\mathrm{x}_{2}$ choice less than 0.25 will limit the maximum allowed oxidation state, which is undesirable. This upper oxidation state is directly controlled by $\mathrm{x}[11,12]$.

Having defined the $\mathrm{x}_{\mathrm{i}}$ value during the first charge (i.e. $\mathrm{x}_{1}=\mathrm{x}_{2}=0.25$ ), two of the three remaining defect parameters in the charged state can be determined from two additional pieces of information, the capacity and the mass change. The third parameter, 
$\mathrm{n}_{2}$, must be defined to allow solution for $\mathrm{y}_{2}$ and $\mathrm{X}_{\mathrm{w} 2}$. Two options are examined here, $\mathrm{n}_{2}=2$ or $\mathrm{n}_{2}=3$ (referred to as case $i$ and case $i i$, respectively). As seen from Figures 4 and 6, 1.63 electrons $/ \mathrm{mol}$ and $6.74 \mathrm{~g} / \mathrm{mol}$, respectively, are exchanged on the first charge. Therefore, equations 10 and 5 are used to give $\mathrm{y}_{2}=0.22$ and $\mathrm{X}_{\mathrm{w} 2}=0.555$ for $\mathrm{n}_{2}=2$, and $\mathrm{y}_{2}=0.23$ and $\mathrm{X}_{\mathrm{w} 2}=0.525$ for $\mathrm{n}_{2}=3$.

It is now possible to calculate the defect parameters for the discharged material. The above parameters for the charged phase together with the capacity and mass change during the first discharge (holding $\mathrm{n}_{1}=0$ and $\mathrm{x}_{1}=0.25$ ) allow calculation of $\mathrm{y}_{1}$ and $\mathrm{X}_{\mathrm{w} 1}$ for case $i$ and for case ii. This sequential process is continued until $\mathrm{y}_{\mathrm{i}}$ and $\mathrm{X}_{\mathrm{wi}}$ are determined for each successive charge and discharge cycle. The results are shown in Figures 10 and 11, respectively. Cycle '0' represents the as-deposited material in these figures.

From the above results, the changes in structure over these 9 cycles are understood as follows. During each charge, the potassium content increases $\left(\mathrm{y}_{2}>\mathrm{y}_{1}\right)$; however, after the first charge, the vacancies are not all filled with potassium ions during charging, and $\mathrm{y}_{2}$ decreases with cycling. The vacancies that do not hold a potassium cation are instead filled with either two or three protons $\left(\mathrm{n}_{2}\right)$, case $i$ or case $i i$, respectively. A material with three protons on the nickel vacancy is consistent with the empirical formula given by Barnard et al. [6,27], for which the point defect representation has been shown to contain three protons on the Ni vacancy [11,12]. As the material is cycled, the potassium content of the discharged phase $\left(\mathrm{y}_{1}\right)$ drops to a lower, but non-zero, constant value, and the charged state $\left(\mathrm{y}_{2}\right)$ has progressively less potassium ions intercalated. This decrease in $y_{2}$ with cycling is clearly seen in Figure 10. The significant difference between case $i$ and case ii is the calculated potassium content in the 
charged state. While case $i$ results in a dramatic change in $y_{2}$ over the ten cycles, case ii displays a more moderate change. This is because case $i i$, with the greater number of protons, requires fewer vacancies to achieve the requisite oxidation state. With cycling, the number of excess protons increases, and the fraction of $\mathrm{Ni}^{4+}$ in the lattice decreases; hence, the average oxidation state of nickel in the charged state decreases (see Figure 5).

The increase in the water content of the films is shown in Figure 11 where the moles of water per mole of nickel $\left(\mathrm{X}_{\mathrm{wi}}\right)$ are tracked as the film is cycled. Both cases $i$ and ii produce the same qualitative effect in the early cycles, with water expulsion during charge and incorporation during discharge. However, for case $i$ these two curves cross so that this behavior is reversed for the later cycles; water is incorporated during charge and pulled out during discharge. This is caused by a more rapid decrease in potassium incorporation during charging for case $i$; the increase in mass is instead accommodated by incorporating more water into the lattice. However, both cases ( $i$ and $i$ ) predict a steady increase in water content on cycling the film. This is consistent with literature observations [13]. This increase in water content is the major cause of the mass increase observed during these 9 cycles. This process explains the electrode swelling phenomenon.

An alternative calculation can be carried out in which the $\mathrm{x}_{1}$ values are allowed to vary on each discharge, and $\mathrm{y}_{1}$ is held constant. Instead of determining the series of $\mathrm{y}_{1}$ and $\mathrm{X}_{\mathrm{w} 1}$ values on each discharge after the first charge (as done above, with $\mathrm{x}_{1}$ and $\mathrm{x}_{2}$ held at 0.25 ), the series of $\mathrm{x}_{1}$ and $\mathrm{X}_{\mathrm{w} 1}$ values can be calculated holding $\mathrm{y}_{1}$ constant at zero after the first cycle. This calculation allows a test of the above assumption that $\mathrm{x}_{\mathrm{i}}$ was both large and constant. Again, $\mathrm{n}_{1}$ is taken to be zero. This results in an $\mathrm{x}$ value of 0.235 , 
a slight decrease from the previous value of 0.25 , and it remains constant for cycles 2 - 9 . For the charge cycles, values of $\mathrm{y}_{2}$ and $\mathrm{X}_{\mathrm{w} 2}$ are found to be similar to those obtained in the above calculation, as are the $X_{w 1}$ values upon discharge. This alternative calculation reiterates the above result, that the primary origin of the decrease in capacity on cycling observed in Figure 3 is caused by a decrease in $\mathrm{y}_{2}$.

The specific result, that $\mathrm{x}_{1}$ and $\mathrm{x}_{2}$ do not change during this cycling, is actually not surprising. As noted in "broad conclusion" number 3 from the five scenarios, a capacity decrease below 1 electron per nickel can occur by either an oxidation state decrease in the charged phase (3.ii and Figure 5) or an oxidation state increase in the discharged phase (3.i). To achieve the latter, $x_{1}$ would have to change. However, Figure 5 shows that the discharged oxidation state is constant after the first cycle, which eliminates the possibility of $\mathrm{x}_{1}$ changing. 


\section{Conclusions}

Experimental capacity (i.e. number of electrons transferred per nickel) and masschange data for thin films of nickel hydroxide were analyzed during cycling using a point defect-containing structural model. Four unique nickel-electrode property variations, and their relation to changes in point defect parameters, were determined:

(i) During the $1^{\text {st }}$ charge, 1.67 electrons per nickel atom were removed from the film, resulting in a maximum nickel oxidation state of 3.67. The large magnitude of this transfer $(>1)$ is a direct result of the 0.25 vacancy content of the cathodically deposited $\alpha$ nickel hydroxide films. Two protons are removed from each vacancy (in addition to the de-intercalation of $1 / 2$ of the interlamellar protons); and in-turn, a $\mathrm{K}^{+}$ion is associated with each vacancy, resulting in a 1.67 electron transfer. While a vacancy content of 0.25 is large, such large values have been discussed by Ruetschi for the $\mathrm{MnO}_{2}$ active material with values of $9 \%$ for electrolytic manganese dioxide [28]. In addition, the authors discussed materials with values as large as $25 \%$, comparable to those proposed in this study.

(ii) During the $1^{\text {st }}$ discharge, 1.0 electrons per nickel atom were added back to the film, resulting in a discharged oxidation state of 2.67. The $\mathrm{K}^{+}$de-intercalates and the nickel vacancy is left vacant, resulting in a 1.0 electron transfer.

(iii) During each successive charge, the upper limit of the nickel oxidation state is diminished, thus diminishing capacity (i.e., capacity fade). This capacity fade occurs because the upper limit of the potassium content decreases while the proton content of the nickel vacancy increases. 
(iv) The water content of the film decreases on charge, increases on discharge, and gradually increases on cycling. This provides for the gradual increase in the total mass of the film and explains the electrode-swelling phenomenon.

This structural variation explains the variable electrochemical properties in terms of varying nonstoichiometry, i.e. changes in the point defect parameters.

\section{Acknowledgements}

The authors gratefully acknowledge the financial support from the Office of Research and Development of the United States Central Intelligence Agency and the US Department of Energy under Cooperative Agreement No. DE-FCO2-91ER75666. 


\section{Notation}

E electrode potential, V

F $\quad$ Faraday's constant, 96487 C/eq.

I applied current, A

$\mathrm{i}_{\mathrm{o}, \mathrm{ox}}$ exchange current for the oxygen evolution reaction, $\mathrm{A}$

$\mathrm{i}_{\mathrm{ox}} \quad$ current expended for oxygen evolution, $\mathrm{A}$

m mass of the film, $g$

M molecular weight of the film, g/mole Ni

$\mathrm{n}$ the average proton occupancy of a nickel vacancy

Ox oxidation state

Q capacity per unit mass of film, C/g

R universal gas constant, $8.314 \mathrm{~J} / \mathrm{mol} \cdot \mathrm{K}$

$\mathrm{T} \quad$ temperature, $\mathrm{K}$

$\mathrm{t} \quad$ time, $\mathrm{s}$

$\mathrm{U}_{\text {ref,ox }}$ standard potential of the oxygen evolution reaction, $\mathrm{V}$

$\mathrm{V}_{\mathrm{Ni}} \quad$ a vacant nickel lattice site

$\mathrm{x} \quad$ moles of vacancies per mole of lattice sites

$\mathrm{X}_{\mathrm{w}} \quad$ moles of water per mole of lattice sites

y moles of vacancies occupied by potassium ions per mole of lattice sites.

$\mathrm{z} \quad$ moles of exchangeable protons on interlamellar $\mathrm{H}^{+}$sites $(0 \leq \mathrm{z} \leq 1)$ 


\section{Greek}

$\alpha_{a} \quad$ anodic transfer coefficient

$\Delta \quad$ change in variable

$\varepsilon \quad$ efficiency of the nickel reaction

$\lambda_{1} \quad$ moles of $\mathrm{OH}^{-}$ions per mole $\mathrm{Ni}$

$\lambda_{2}$ moles of $\mathrm{K}^{+}$ions per mole $\mathrm{Ni}$

$\lambda_{3} \quad$ moles of water per mole $\mathrm{Ni}$

$\lambda_{4}$ number of electrons per mole $\mathrm{Ni}$

\section{Subscript}

1 discharged state, nickel hydroxide

2 charged state, oxyhydroxide

\section{Superscript}

$0 \quad$ as-deposited film 


\section{References:}

1. McBreen J (1990), Editor, The Nickel Oxide Electrode, Plenum Press.

2. Delichere P, Joiret S, Hugot-le Goff A, Bange K, and Hetz B (1988), J. Electrochem. Soc., 135, 1856.

3. Carpenter MK, Conell RS, and Corrigan DA (1987), Solar Energy Mater., 16, 333.

4. Gross S (1977), Review of Electrochemical Impregnation of Nickel Cadmium Cells, Jet Propulsion Laboratory, Pasadena.

5. Barnard R, Randall CF, and Tye FL (1980), J. Appl. Electrochem., 10, 109.

6. Barnard R, Randall CF, and Tye FL (1981), J. Appl. Electrochem., 11, 517.

7. Kim M, Hwang T, and Kim K (1997), J. Electrochem. Soc., 144, 1537.

8. Kim M and Kim K (1998), J. Electrochem. Soc., 145, 507.

9. Timmerman P, Ratnakumar BV, and Di Stefano S (1996), Aqueous Batteries, P. D. Bennet and S. Gross, Eds., PV 96-16, p. 130, The Electrochemical Society Proceedings Series, Pennington, NJ.

10. Bode H, Dehmelt K, and Witte J (1969), Z. anorg. Chem., 366, 1.

11. Cornilsen BC, Karjala PJ, and Loyselle PL (1988), J. Power Sources, 22, 351.

12. Cornilsen BC, Shan X, and Loyselle PL (1990), J. Power Sources, 29, 453.

13. Cheek GT and O'Grady WE (1997), J. Electroanal. Chem., 421, 173.

14. Bernard P, Gabrielli C, Keddam M, Takenouti H, Leonardi J, and Blanchard P (1991), Electrochim. Acta, 36, 743.

15. Mo Y, Hwang E, and Scherson DA (1996), J. Electrochem. Soc., 143, 37. 
16. Cordoba-Torresi SI, Gabrielli C, Hugot-Le Goff A, and Torresi R, $J$. Electrochem. Soc., 138, 1548.

17. Haring P and Kotz R (1995), J. Electroanal. Chem., 385, 273.

18. Kowal A, Niewiara R, Peronczyk B, and Haber J (1996), Langmuir, 12, 2332.

19. Kalu EE, Srinivasan V, Nwaoga T, and Weidner JW (1999), Selected Battery Topics, G. Halpert, M. L. Gopikanth, K. M. Abraham, W. R. Cieslak, and W. A. Adams, Eds., PV 98-15, p. 639, The Electrochemical Society Proceedings Series, Pennington, NJ.

20. Streinz CC, Hartman AP, Motupally S, and Weidner JW (1995), J. Electrochem. Soc., 142, 1084.

21. Barnard R, Randell CF, and Tye FL (1981), J. Appl. Electrochem., 11, 517.

22. Corrigan DA and Knight SL (1989), J. Electrochem. Soc., 136, 613.

23. Loyselle PL, Karjala PJ, and Cornilsen BC (1986), Electrochemical and Thermal Modeling of Battery, Fuel Cell and Photoenergy Conversion Systems, R. J. Selman and H. C. Maru, Eds., PV 86-12, p. 114, The Electrochemical Society Proceedings Series, Pennington, NJ.

24. Streinz CC, Motupally S, and Weidner JW (1995), J. Electrochem. Soc, 143, 4051.

25. Srinivasan V, Weidner JW, and Newman J (2001), J. Electrochem. Soc., 148, A969.

26. Bode H, Dehmelt K, and Witte J (1966), Electrochim. Acta, 11, 1079.

27. Barnard R and Randall CF (1982), J. Appl. Electrochem., 12, 27.

28. Ruetschi P (1984), J. Elelctrochem. Soc., 131, 2737. 


\section{Table Caption}

Table 1. The five scenarios, generated from five unique combinations of defect parameters, used to generate the number of electrons transferred in Figures 8 and 9. When $\mathrm{y}_{2}=\mathrm{x}_{2}$, none of the nickel vacancies are occupied by protons and therefore $\mathrm{n}_{2}$ is zero. The parameters that vary in a given scenario are assumed to change linearly with cycle number. For all five scenarios listed above, the number of protons on the nickel vacancies of the as-deposited material is 2.0 (i.e. the initial oxidation state is 2.0). NA = not applicable.

\section{Figure Captions}

Figure 1. Schematic of the nickel hydroxide active material deposited using the cathodic precipitation technique. The reactions occurring on charge are sketched in the figure.

Figure 2. First two constant current $(0.1 \mathrm{~mA})$ charge/discharges for a $70 \mu \mathrm{g}$ nickel hydroxide film. The $\times$ represents the point where the electrode is fully charged or discharged; these endpoints were used in the generation of Figure 3.

Figure 3. Capacity on charge and discharge vs cycle number for a $70 \mu \mathrm{g}$ nickel hydroxide film (not yet corrected for oxygen evolution). The plot was generated from data similar to that shown in Figure 2. The values plotted are an average of 3-4 data sets, and the error bars represent the spread in the data.

Figure 4. Number of electrons transferred per Ni during charge and discharge of a $70 \mu \mathrm{g}$ nickel hydroxide film. The charge/discharge values from Figure 3 have been corrected for the oxygen evolution reaction as described in the text. The values 
plotted are an average of 3-4 data sets, and the error bars represent the spread in the data.

Figure 5. Average nickel oxidation state during cycling of a $70 \mu \mathrm{g}$ nickel hydroxide film, as calculated from the initial oxidation state of the as-deposited material (2.0) and the number of electrons transferred (from Figure 4).

Figure 6. Variation of film mass during charge/discharge of a $70 \mu$ g nickel hydroxide film. The mass increases during charge and decreases during discharge, as measured using the EQCM. The current used is $0.1 \mathrm{~mA}$.

Figure 7. Molecular weight variation during charge/discharge of a $70 \mu \mathrm{g}$ nickel hydroxide film. The molecular weight increases during charge and decreases during discharge. The values plotted are an average of 3-4 data sets, and the error bars represent the spread in the data. The molecular weight of the as deposited material is $121 \mathrm{~g} / \mathrm{mole} \mathrm{Ni}$.

Figure 8. Number of electrons transferred per nickel during charge (top) and discharge (bottom) for scenarios 1-3, as defined in Table 1. The number of electrons transferred is calculated using equation 10 .

Figure 9. Number of electrons transferred per nickel during charge (top) and discharge (bottom) for scenarios 4-5, as defined in Table 1. The number of electrons transferred is calculated using equation 10.

Figure 10. The variation in the defect parameters with cycling. The defect parameters were extracted using the model and the experimental capacity and mass change data (Figures 4 and 7). The $\mathrm{n}_{1}$ value is 2 for the as-deposited film, and 0 for the 
other films. The two different options for $\mathrm{n}_{2}$ (2 or 3 ) lead to two different values of $y_{2}$. The values of $y_{1}$ and $x$ are the same for both options.

Figure 11. The variation in water content with cycling. The water content was extracted using the model and the experimental capacity and mass changes (Figures 4 and 7). The $\mathrm{n}_{1}$ value is 2 for the as-deposited film, and 0 for the other films. The $\mathrm{Xw}_{2}$ values in the charged state (dotted lines) differ for the two $\mathrm{n}_{2}$ options, but $\mathrm{Xw}_{1}$ values in the discharged material (solid line) do not differ with a change in $\mathrm{n}_{2}$. 
Srinivasan et al., Table 1

\begin{tabular}{|c|c|c|c|c|c|c|}
\hline Name & $\mathbf{x}_{1}$ & $\mathbf{x}_{2}$ & $\mathbf{y}_{1}$ & $\mathbf{y}_{2}$ & $\mathbf{n}_{1}$ & $\mathbf{n}_{2}$ \\
\hline Scenario 1 & 0.25 & 0.25 & $0 \rightarrow 0.25$ & $\mathrm{x}_{2}$ & 0 & $\mathrm{NA}$ \\
Scenario 2 & $0.25 \rightarrow 0.11$ & $0.25 \rightarrow 0.11$ & 0 & $\mathrm{x}_{2}$ & 2 & $\mathrm{NA}$ \\
Scenario 3 & $0.11 \rightarrow 0.25$ & $0.11 \rightarrow 0.25$ & 0 & $\mathrm{x}_{2}$ & 0 & $\mathrm{NA}$ \\
Scenario 4 & 0.25 & 0.25 & 0 & $0.25 \rightarrow 0.11$ & 0 & 2 \\
Scenario 5 & $0.25 \rightarrow 0.11$ & $0.25 \rightarrow 0.11$ & 0 & $0.25 \rightarrow 0$ & 0 & 2 \\
\hline
\end{tabular}

Table 1. The five scenarios, generated from five unique combinations of defect parameters, used to generate the number of electrons transferred in Figures 8 and 9. When $\mathrm{y}_{2}=\mathrm{x}_{2}$, none of the nickel vacancies are occupied by protons and therefore $\mathrm{n}_{2}$ is zero. The parameters that vary in a given scenario are assumed to change linearly with cycle number. For all five scenarios listed above, the number of protons on the nickel vacancies of the as-deposited material is 2.0 (i.e. the initial oxidation state is 2.0 ). NA = not applicable. 
Srinivasan et al., Figure 1

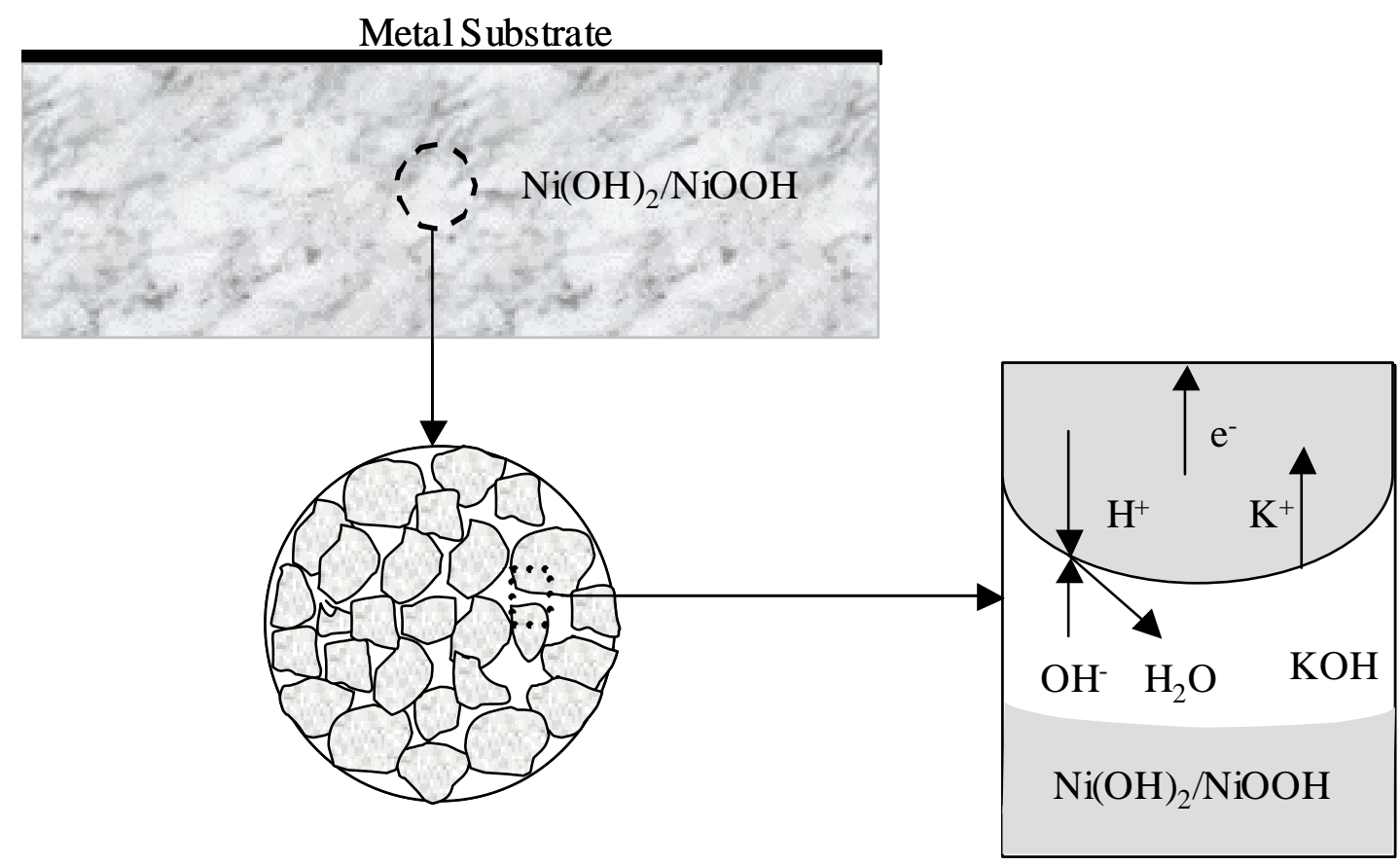

Figure 1. Schematic of the nickel hydroxide active material deposited using the cathodic precipitation technique. The reactions occurring on charge are sketched in the figure. 
Srinivasan et al., Figure 2

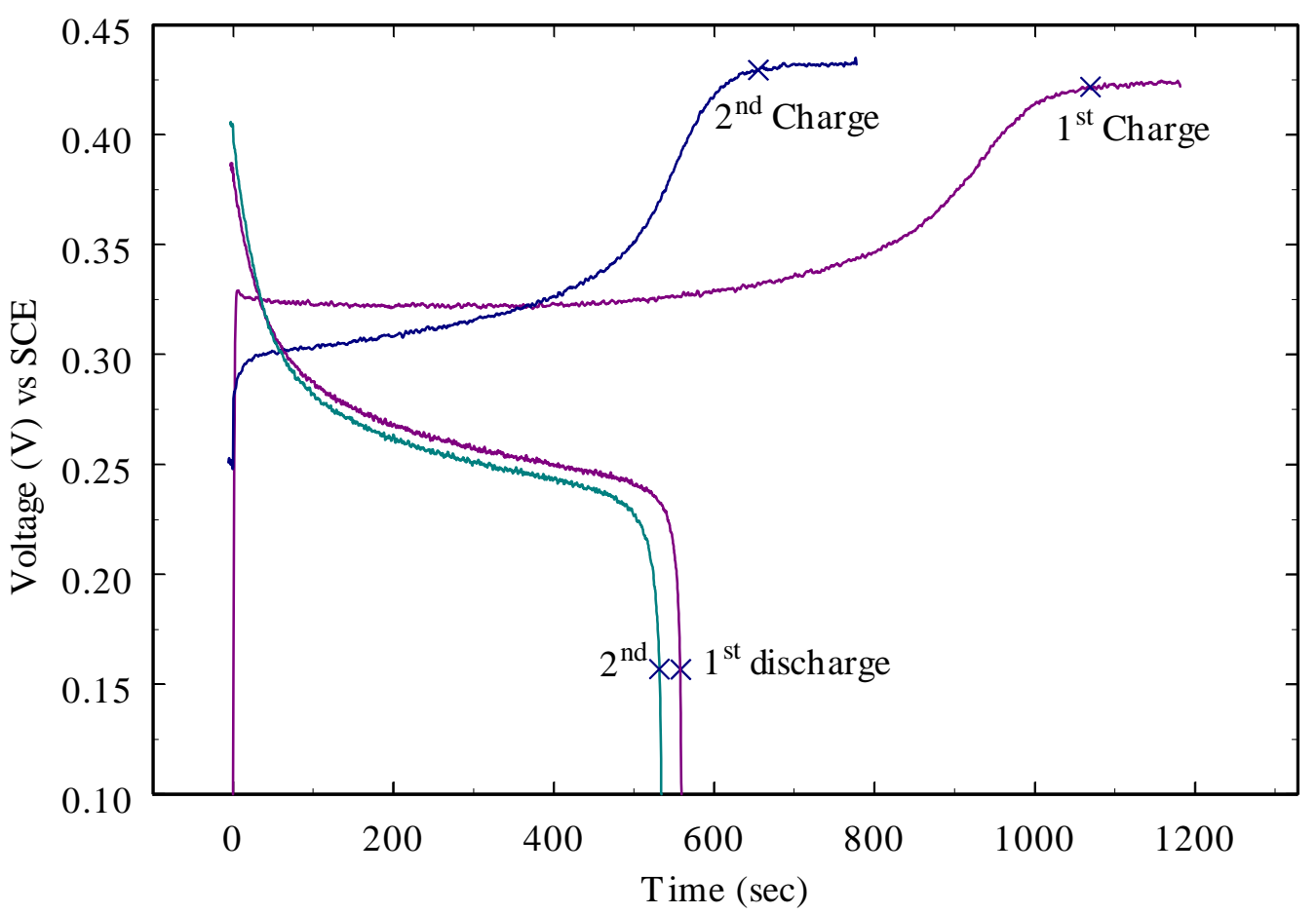

Figure 2. First two constant current $(0.1 \mathrm{~mA})$ charge/discharges for a $70 \mu$ g nickel hydroxide film. The $\mathrm{x}$ represents the point where the electrode is fully charged or discharged; these endpoints were used in the generation of Figure 3. 
Srinivasan et al., Figure 3

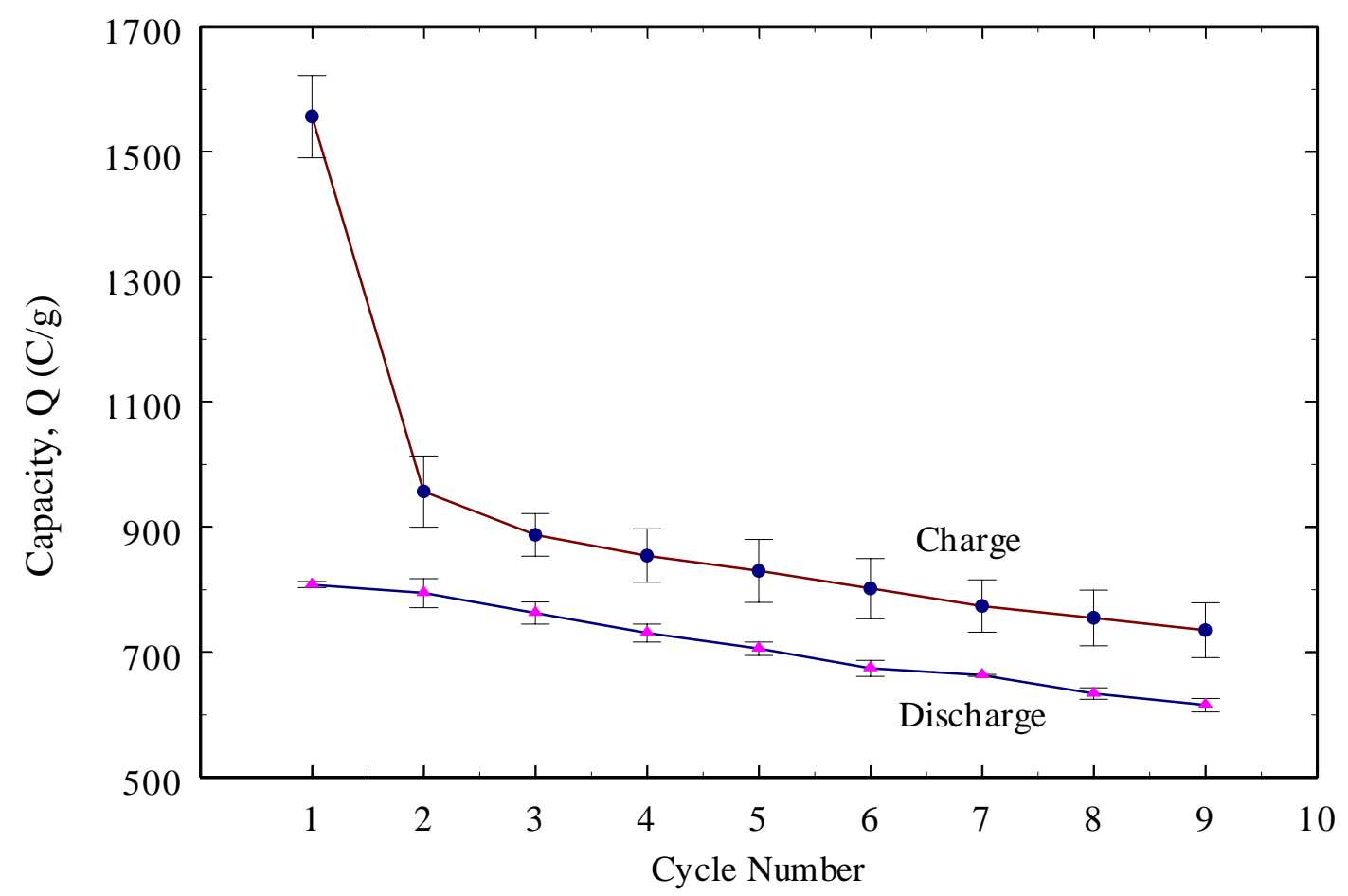

Figure 3. Capacity on charge and discharge vs cycle number for a $70 \mu \mathrm{g}$ nickel hydroxide film (not yet corrected for oxygen evolution). The plot was generated from data similar to that shown in Figure 2. The values plotted are an average of 3-4 data sets, and the error bars represent the spread in the data. 
Srinivasan et al., Figure 4

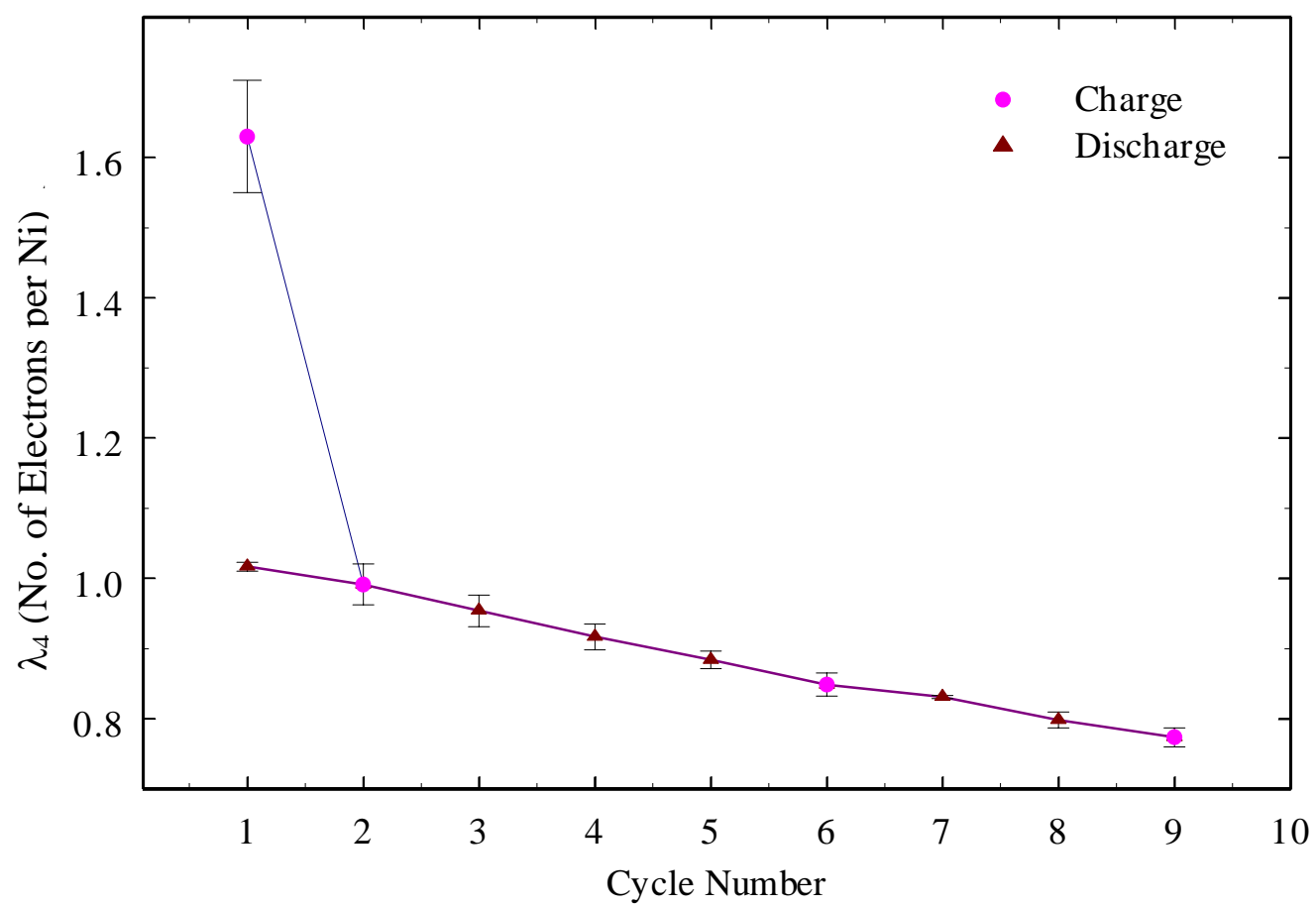

Figure 4. Number of electrons transferred per Ni during charge and discharge of a $70 \mu \mathrm{g}$ nickel hydroxide film. The charge/discharge values from Figure 3 have been corrected for the oxygen evolution reaction as described in the text. The values plotted are an average of 3-4 data sets, and the error bars represent the spread in the data. 
Srinivasan et al., Figure 5

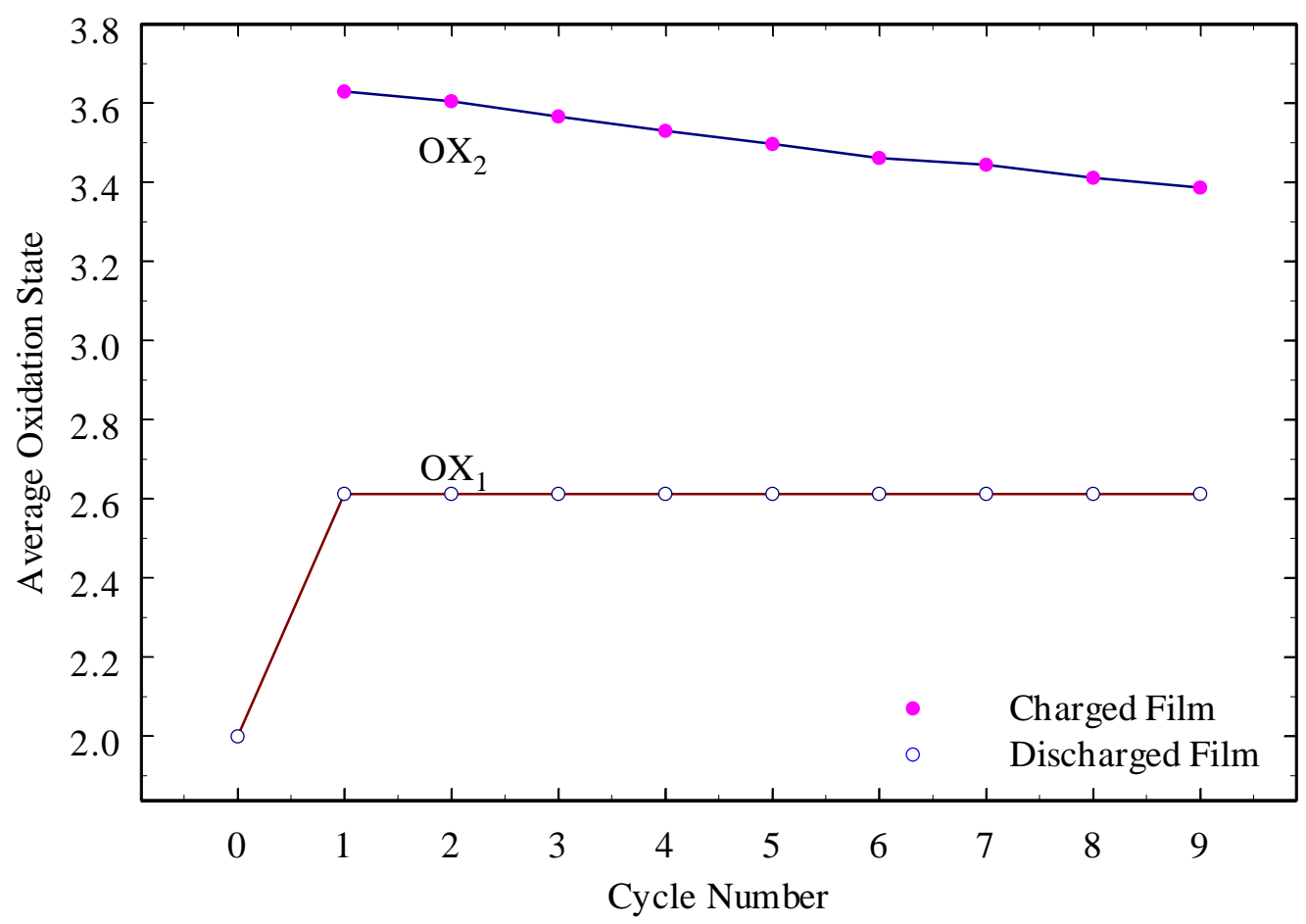

Figure 5. Average oxidation state during cycling of a $70 \mu \mathrm{g}$ nickel hydroxide film, as calculated from the initial oxidation state of the as-deposited material (2.0) and the number of electrons transferred (from Figure 4). 
Srinivasan et al., Figure 6

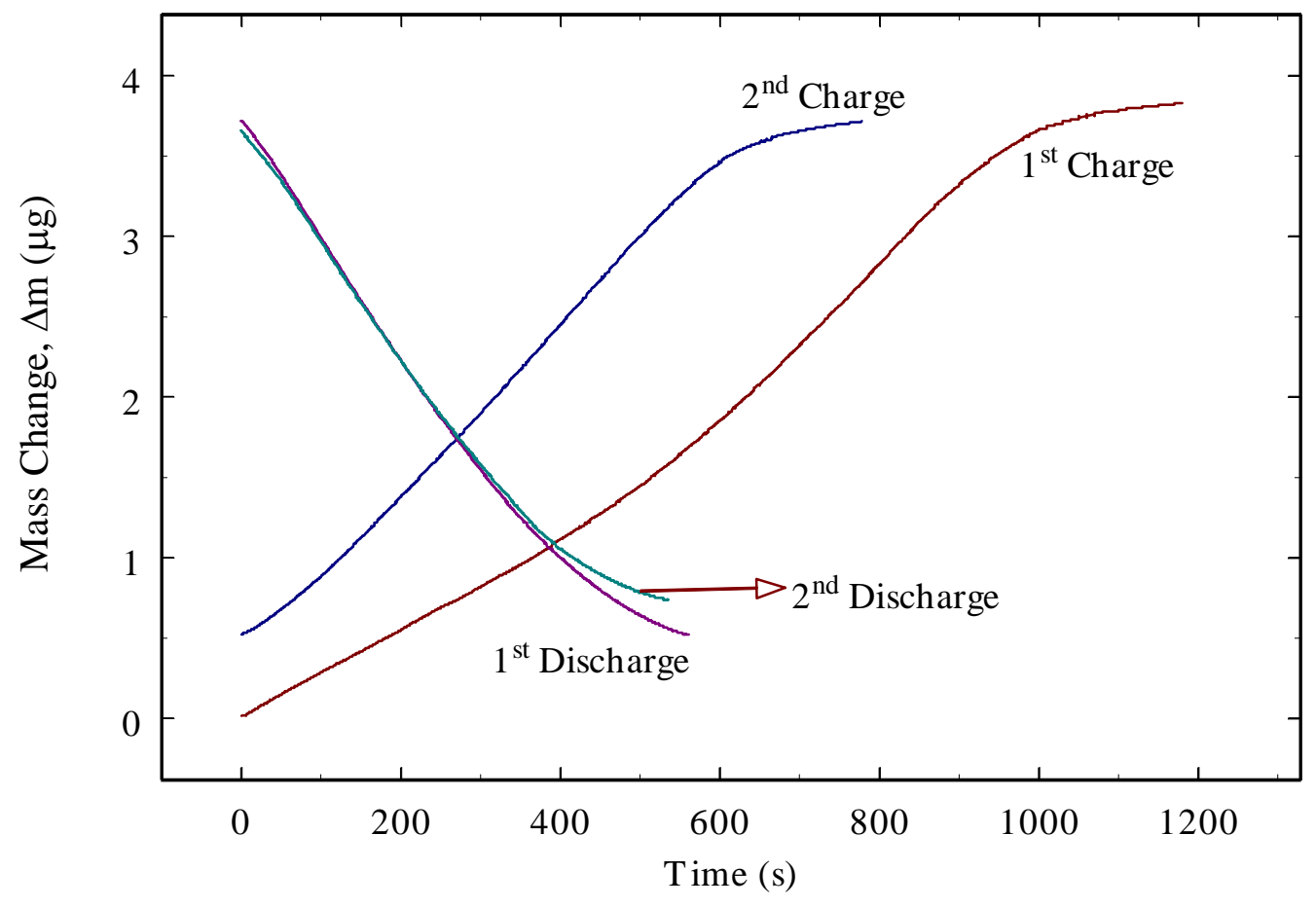

Figure 6. Variation of film mass during charge/discharge of a $70 \mu \mathrm{g}$ nickel hydroxide film. The mass increases during charge and decreases during discharge, as measured using the EQCM. The current used is $0.1 \mathrm{~mA}$. 
Srinivasan et al., Figure 7

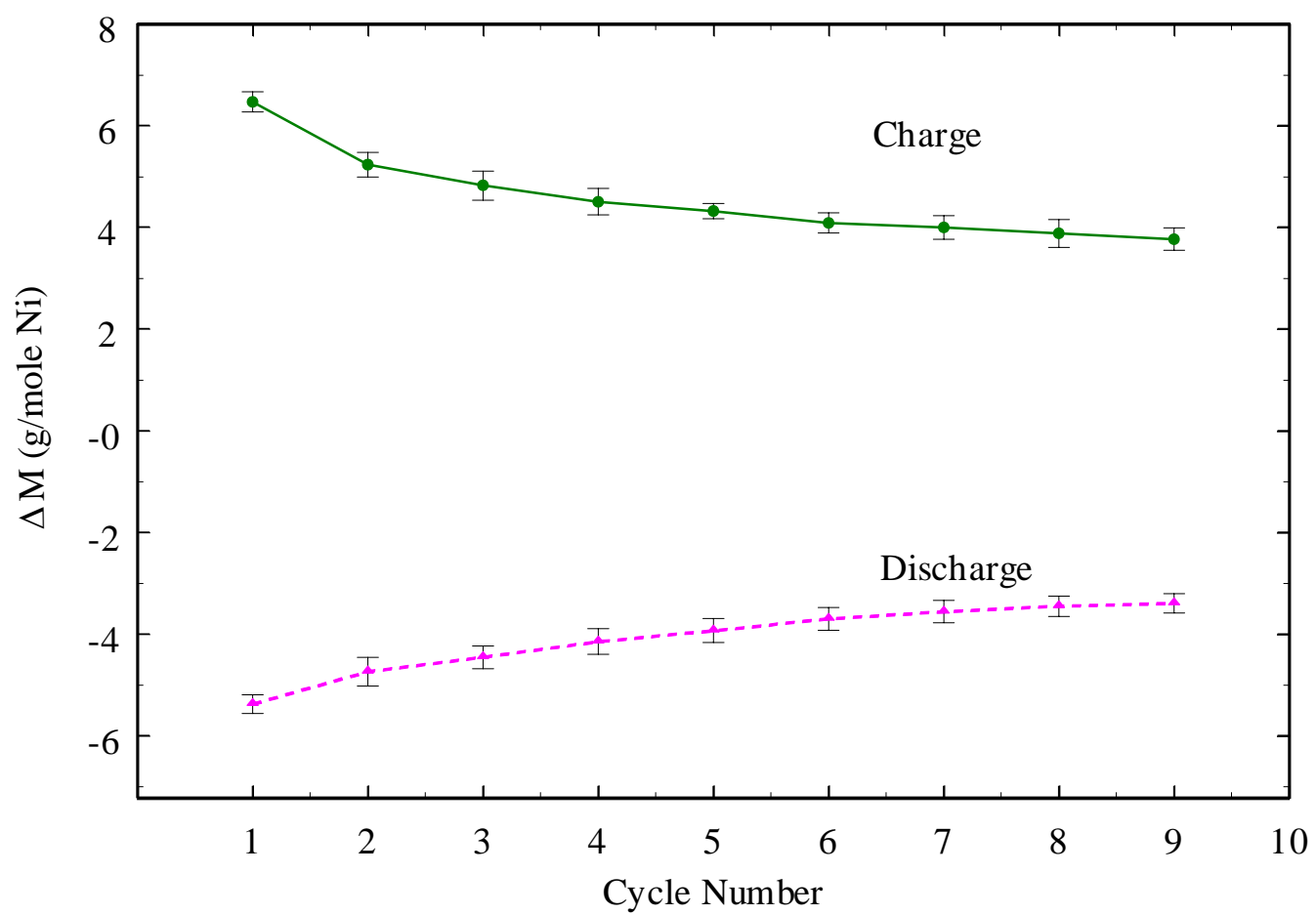

Figure 7. Molecular weight variation during charge/discharge of a $70 \mu$ nickel hydroxide film. The molecular weight increases during charge and decreases during discharge. The values plotted are an average of 3-4 data sets, and the error bars represent the spread in the data. The molecular weight value of the as-deposited material is $121 \mathrm{~g} / \mathrm{mole}$ of $\mathrm{Ni}$. 
Srinivasan et al., Figure 8

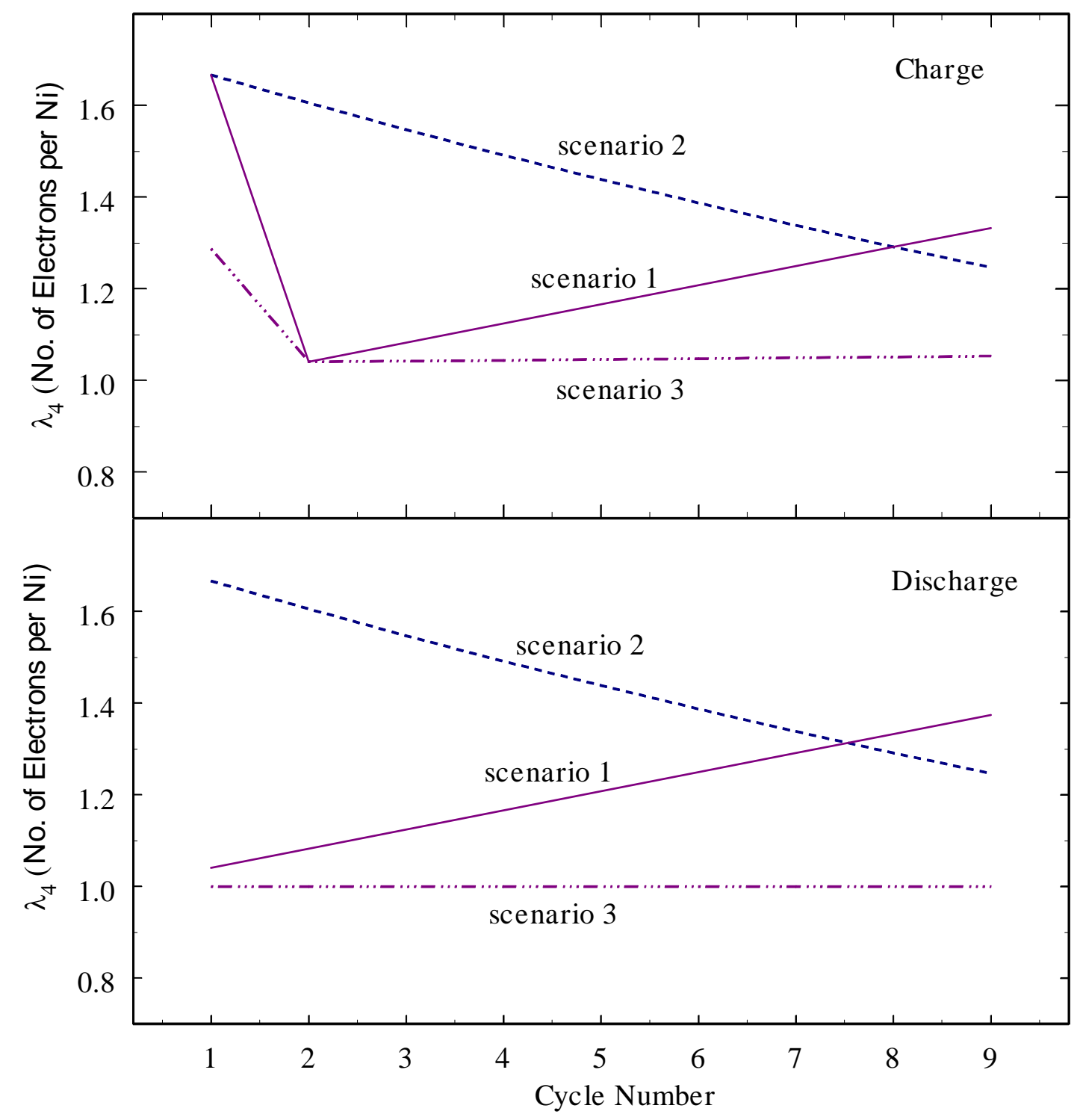

Figure 8. Number of electrons transferred per nickel during charge (top) and discharge (bottom) for scenarios 1-3, as defined in Table 1. The number of electrons transferred is calculated using equation 10 . 
Srinivasan et al., Figure 9

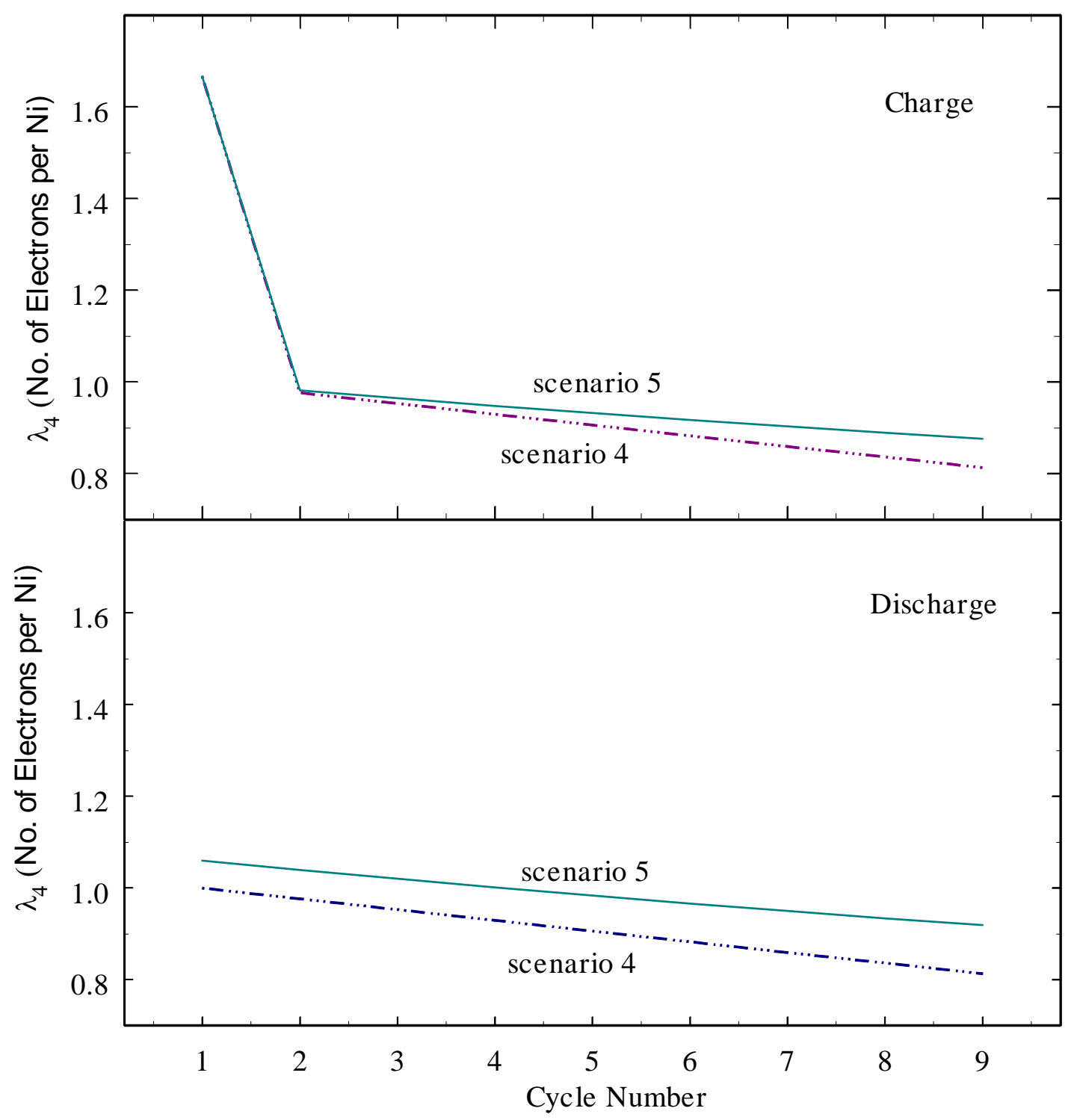

Figure 9. Number of electrons transferred per nickel during charge (top) and discharge (bottom) for scenarios 4-5, as defined in Table 1. The number of electrons transferred is calculated using equation 10 . 
Srinivasan et al., Figure 10

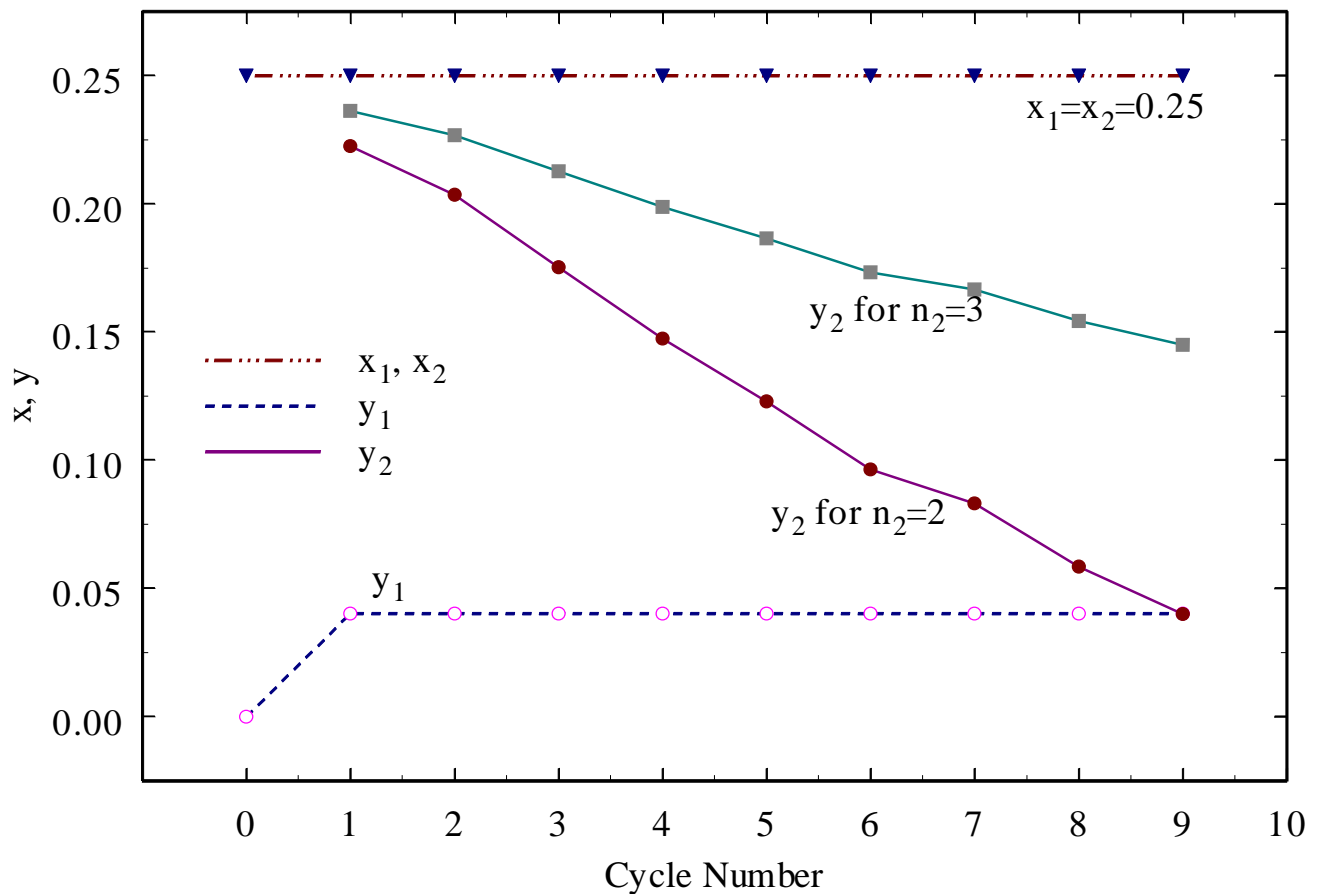

Figure 10. The variation in the defect parameters with cycling. The defect parameters were extracted using the model and the experimental capacity and mass change data (Figures 4 and 7). The $n_{1}$ value is 2 for the as-deposited film, and 0 for the other films. The two different options for $\mathrm{n}_{2}$ (2 or 3) lead to two different values of $\mathrm{y}_{2}$. The values of $\mathrm{y}_{1}$ and $\mathrm{x}$ are the same for both options. 


\section{Srinivasan et al., Figure 11}

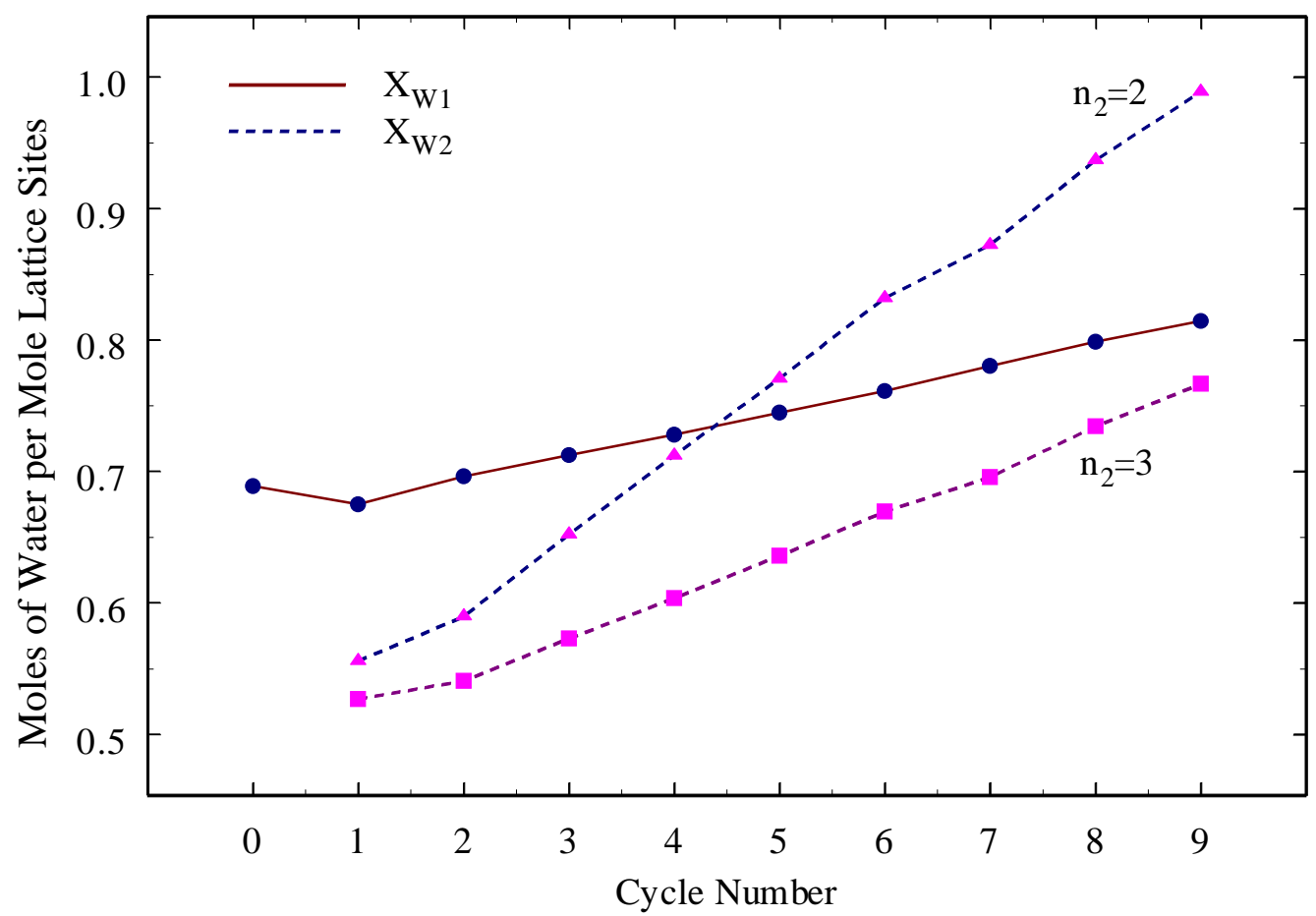

Figure 11. The variation in water content with cycling. The water content was extracted using the model and the experimental capacity and mass changes (Figures 4 and 7). The $\mathrm{n}_{1}$ value is 2 for the as-deposited film, and 0 for the other films. The $\mathrm{Xw}_{2}$ values in the charged state (dotted lines) differ for the two $\mathrm{n}_{2}$ options, but $\mathrm{Xw}_{1}$ values in the discharged material (solid line) do not differ with a change in $\mathrm{n}_{2}$. 